\title{
La Ley de modernización del Gobierno local: función de Gobierno, funciones directivas y funcionarios con habilitación de carácter nacional
}

\author{
Federico A. Castillo Blanco \\ Profesor Titular de Derecho Administrativo de la Universidad de Granada.
}

\begin{abstract}
Sumario: I. INTRODUCCIÓN: ¿QUIÉN SE HA LLEVADO MI QUESO? O LA NECESIDAD DE ASUMIR LOS CAMBIOS QUE SE HAN PRODUCIDO EN NUESTRAS ENTIDADES LOCALES. II. EL DEVENIR DE LOS FUNCIONARIOS CON HABILITACIÓN DE CARÁCTER NACIONAL EN EL RÉGIMEN LOCAL CONSTITUCIONAL. 1. Un breve apunte histórico o cómo y por qué los Cuerpos Nacionales entraron en crisis tras la aprobación de la Constitución y la articulación del régimen local postconstitucional. 2. Los Cuerpos Nacionales de Administración Local tras la Constitución de 1978: acentuación de la crisis de éstos e insatisfacción de los funcionarios que los sirven. III. LOS CAMBIOS QUE SE HAN PRODUCIDO EN EL ENTORNO DE NUESTRAS ENTIDADES LOCALES Y EN LA FORMA DEL GOBIERNO LOCAL COMO CLAVES PARA REDEFINIR A LOS CUERPOS NACIONALES DE ADMINISTRACIÓN LOCAL. 1. Breve alusión a los elementos que condicionan al régimen local español. 2. Las carencias del sistema de dirección política y de función directiva: su incidencia en los funcionarios con habilitación de carácter nacional. IV. LAS MEDIDAS CONTEMPLADAS EN LA LEY DE LEY DE MODERNIZACIÓN DEL GOBIERNO LOCAL. 1. El ámbito de aplicación de las medidas a adoptar, la definición de lo básico en dicha norma y el ejercicio de la acción de gobierno en el ámbito local. 2. La función directiva. 3. Los funcionarios con habilitación de carácter nacional. V. A MODO DE RECAPITULACIÓN Y SÍNTESIS: ALGUNAS PROPUESTAS PARA LA ESTRUCTURACIÓN DE LA FUNCION DIRECTIVA EN LOS GOBIERNOS LOCALES Y LA DEFINICIÓN DE LAS FUNCIONES RESERVADAS A LOS FUNCIONARIOS CON HABILITACIÓN DE CARÁCTER NACIONAL.
\end{abstract}

\section{INTRODUCCIÓN: ¿QUIÉN SE HA LLEVADO MI QUESO? O LA NECESIDAD DE ASUMIR LOS CAMBIOS QUE SE HAN PRODUCIDO EN NUESTRAS ENTIDADES LOCALES}

Un célebre libro, que es considerado un auténtico best-seller en el ámbito de la dirección de las organizaciones, relata, en un lenguaje metafórico y didáctico en el que los protagonistas son dos ratones y dos liliputienses, una realidad incuestionable que no hace sino obedecer al más simple sentido común, y que consiste en que, querámoslo o no y bien que nos pese en la mayoría de las circunstancias, en nuestras vidas, personales o 
profesionales, estamos sometidos a lo largo de éstas a distintos y variados procesos de cambio en los parámetros y contextos en que se desenvuelven. El reto, si se desea encontrar una nueva oportunidad profesional, familiar o personal — un nuevo depósito de queso en el libro a que nos referimos-, será adoptar una actitud positiva frente a las nuevas circunstancias, no mantener los mismos paradigmas que guiaban nuestra actitud con anterioridad en un contexto pergeñado por parámetros distintos, olvidar los temores y desprendernos de los lamentos continuos frente a la nueva situación que paralizan nuestra actitud y no nos permiten afrontar la misma con la solvencia requerida. Por último, haciendo un rápido y breve resumen de los distintos mensajes contenidos en el ensayo anteriormente mencionado, mantenernos siempre alerta frente a esos probables cambios es una actitud adecuada y necesaria que ha de mantenerse de forma permanente.

No estoy tratando, con este comienzo, de articular una lección de formación directiva y, desde luego, en ningún caso reprochar al colectivo de funcionarios con habilitación de carácter nacional en su integridad, importante sin duda alguna en la construcción institucional de nuestra Administración Local, una eventual actitud pasiva y reactiva frente a los cambios que, de forma inequívoca, se vienen produciendo en nuestras entidades locales en los últimos veinticinco años. Simplemente creo que es preciso partir de que, como ahora expondré, la intensidad y el ritmo de los cambios producidos en la esfera local no pueden dejar inerme ni a la organización del gobierno local, ni a la función pública local ni, parece obvio tras la afirmación anterior, a los actuales funcionarios con habilitación de carácter nacional. Aferrarse al antiguo queso, esperar que el mismo tenga idénticas características a las que tenía hasta entonces, es una actitud muy parecida a la de HEM, uno de los liliputienses a que me referí con anterioridad, que se niega y se resiste al cambio por temor a que conduzca a algo peor y con ella empeora sus circunstancias, y no a la de HAW que aprende a adaptarse a tiempo en cuanto comprende que los cambios también pueden conducir a algo mejor y que, en la historia comentada, realiza una reflexión clave que transformará su actitud y la cambiará: SI NO CAMBIAS TE PUEDES EXTINGUIR.

Pues bien, ciertamente, es muy frecuente en nuestra función pública, ya sea en los colectivos de funcionarios o en la representación colectiva de éstos, olvidarse o no partir de un axioma que considero esencial y que no es otro que la función pública es un sistema instrumental dirigido a proporcionar unos recursos humanos, profesionales y motivados, a nuestras organizaciones públicas en orden a la satisfacción de los intereses genera- 
les a éstas encomendados. Si como seguramente coinciden conmigo, la sociedad española y la propia Administración española, han experimentando y continúan experimentando importantes cambios no estará de más - si se olfatea el queso para ver cuando comienza a enmohecerse- aceptar que nuestro sistema de función pública, y lógicamente la función pública local, han de experimentar ciertos cambios y, en otros supuestos, profundizar en rasgos característicos del sistema de función pública tradicional para responder a la función constitucional que a la misma se le asigna. En caso contrario el propio sistema de función pública comienza a ponerse en cuestión. Y eso es, precisamente, algo de lo ocurrido en los últimos años en nuestro sistema en que, de una parte, los procesos de laboralización y, de otra, la sistemática y reiterada utilización de fórmulas jurídico-privadas en la prestación de servicios públicos ponen de manifiesto, entre otros muchos aspectos, uno que me parece evidente en el caso que nos ocupa: el sistema de función pública español, incluso tras las reformas acontecidas en 1984 y 1987, y sus modificaciones posteriores, sigue anclado en unos parámetros que no parecen dejar satisfechos a nadie. Ni los responsables políticos, ni los ciudadanos en general, ni mayoritariamente la doctrina científica que se ocupa del tema ni, a fuerza de ser sincero, los propios funcionarios, que desearían un mayor reconocimiento de su dignidad profesional y una adecuada recompensa de su contribución a las organizaciones, se sienten cómodos en el actual sistema. Y, sin embargo, no podemos olvidarnos que construir una institución como nuestra burocracia profesional nos ha llevado algunas decenas de años y que la solución a los males del sistema no se encuentra en la voladura, ni siquiera controlada, de éste, sino en su necesaria reforma.

Es más, y ya adelanto una de las conclusiones de este trabajo, difícilmente puede abordarse una reforma adecuada de los funcionarios con habilitación de carácter nacional sin enmarcarla, de forma sistemática, en una más general del sistema de función pública y del sistema de función pública local más específicamente. Pero a todo esto nos referiremos oportunamente. Y refirámonos, en primer término, a la historia de estos cuerpos nacionales para tratar de indagar las causas que puedan haber conducido a una eventual crisis de los mismos. 


\section{EL DEVENIR DE LOS FUNCIONARIOS CON HABILITACIÓN DE CARÁCTER NACIONAL EN EL RÉGIMEN LOCAL CONSTITUCIONAL}

\section{Un breve apunte histórico o cómo y porqué los Cuerpos Nacionales entraron en crisis tras la aprobación de la Constitución y la articulación del régimen local postconstitucional.}

Es suficientemente conocido que los Cuerpos Nacionales de Administración Local se consolidan como cuerpos funcionariales en plena Dictadura de Primo de Rivera ${ }^{1}$. Bien es cierto que su definitiva estructuración tiene un origen concreto al calor de la conciencia extendida en todo el país sobre las corruptelas y los problemas de legalidad que eran moneda de uso común en las entidades locales españolas desde la Restauración y que determinaron tanto el fortalecimiento de dichos Cuerpos como la creación del Servicio de Inspección y Asesoramiento a las entidades locales. Las medidas para ello bascularon en tres direcciones que condicionarán históricamente la función de estos cuerpos: la de ser miembros de la Corporación, la advertencia de ilegalidad y el régimen de acceso a través de la oposición. Con posterioridad se producirá la estatización de estos Cuerpos y su definitiva articulación a través de la Ley de Bases de Régimen Local de 1945 y el posterior texto articulado de 1950 que establecerá cuatro Cuerpos Nacionales: Secretarios, Interventores, Depositarios y Directores de Bandas de Música (?).

En cualquier caso, la comprensión correcta de la inserción de estos funcionarios en la organización municipal, y respecto de los cuales el Estado

\footnotetext{
${ }^{1}$ Por todos los trabajos puede consultarse A. Bullón Ramírez, Historia del Secretariado de Administración Local, Madrid, 1966; J. CARRASCo Belinchón, Pasado, presente y futuro del Secretario de Administración Local, Diputación Provincial de La Coruña, 1972; J.L. De Simón Tobalina, «Status histórico, actual y futuro de los Secretarios de Administración Local», REVL n 207, 1980. En aquellos Cuerpos Nacionales cuyas funciones vienen vinculadas a la gestión económico-financiera y recaudatoria son de especial interés los de A. NIETO, «Historia y Elegía de los Depositarios de Fondos de Administración Local», REALA, n 234, 1987 y V.J. ArNau BERNIA, «Los interventores de Administración Local y las funciones de control interno», Revista de Hacienda Local, $\mathrm{n}^{\circ}$ 72, 1994. Más recientemente I. AgirRezcuenaGa, Origen de los funcionarios locales de habilitación estatal: Los cuerpos nacionales, IVAP, Bilbao, 1996, o el de R. MARTín MATEO, «Los cuerpos nacionales de Administración Local», REAL, $\mathrm{n}^{\circ} 285,2001$, págs. 51 y ss.. Bien es cierto que AGIRREZCUENAGA ha puesto de relieve que, aunque su consagración como Cuerpos se produce con el Estatuto Municipal de 1924, lo cierto es que durante todo el s. XIX, durante la Restauración pero inclusive antes desde las Cortes de Cádiz, la figura del Secretario Municipal o Provincial, el Contador — cuya denominación por cierto pervive en algunos países de América Latina— o el Depositario está presente de una u otra forma, con mayores o menores garantías para el ejercicio de su función, y con peores o mejores avatares.
} 
juega un papel esencial, no puede olvidar un dato relevante que, a nuestro juicio, explica en gran medida la aparición de los mismos y su relativa dependencia del poder central. Me refiero, en concreto, a la concepción clásica de nuestro régimen local a partir del s. $\mathrm{XIX}^{2}$, fuertemente inspirado en la tradición continental de inspiración francesa ${ }^{3}$, y a su vez alejado de los principios del selfgoverment ${ }^{4}$, y en el que los municipios se entendía que formaban parte del poder ejecutivo y dependientes del jefe político nombrado por el Rey ${ }^{5}$, eran por decirlo en palabras del Conde de Toreno subalternos del poder ejecutivo aunque su elección fuese, ciertamente, particular al ser elegidos por sus convecinos para un mejor gobierno de los municipios (aunque ciertamente la elección del Alcalde fue un punto de honda discusión a lo largo de todo el s. XIX y en el que la elección de éste por procedimientos democráticos fue puramente anecdótica), pero la soberanía y su representación correspondía exclusivamente al Congreso nacional ${ }^{6}$. De esta forma, como indica PosADA, al referirse a las palabras del Conde de Toreno, se perfila el sistema administrativo que en aquellos momentos comienza a construirse en España, basado en el reconocimien-

\footnotetext{
${ }^{2}$ Un estudio muy documentado y serio puede encontrarse en J. GARCíA Fernández, El origen del municipio constitucional, IEAL, Madrid, 1983 y en el que pone de manifiesto que la centralización en Francia, que tanto influenciará el municipalismo de las Cortes de Cádiz, no respondía al primer ordenamiento municipal de la Francia revolucionaria que sí atribuyó un ámbito de competencias privativas al municipio, sino a la posterior rectificación fruto de la crisis de dominación de la burguesía que se expresa en la reacción termidoriana y que culmina el 18 de brumario. Asimismo, indica que, frente al caso francés, los avatares del Estado constitucional en España determinaron que el municipio se convirtiese en un reducto de acción de la burguesía revolucionaria partidaria, por tanto, de su fortalecimiento, y, por el contrario, la aristocracia terrateniente alidada con la burguesía reaccionaria reaccionara de forma inversa a Francia apoyando la centralización. En palabras del autor «Así nace el municipio moderado, que es disímil del municipio doctrinario francés (pág. 341).

${ }^{3}$ Sobre el sentido del municipalismo en Francia, y con ello los principios que fundamentaron su traslación al sistema de régimen local español, son imprescindibles los trabajos de E. GARCÍA DE ENTERRÍA, «E. Turgot y los orígenes del municipalismo moderno», $R A P \mathrm{n}^{\circ} 33$, págs. 79 y ss. y «Los fundamentos del Régimen Municipal Francés», REVL n ${ }^{\circ} 17$, 1961, pág. 321

${ }^{4}$ Aunque, ciertamente, sin olvidar la tradición municipal española de la edad media castellana, aunque si apartándose de la decadencia del régimen municipal en el absolutismo monárquico. Puede verse a este respecto, y respecto de las discusiones que en las Cortes de Cádiz se suscitaron respecto del modelo de Administración Local, A. PosADA, Evolución legislativa del Régimen Local en España 1812-1909, Instituto de Estudios de Administración Local, Madrid, 1982, págs. 47 y ss.

${ }^{5}$ Véase en cuanto a la evolución del régimen municipal y su consagración en las Cortes de Cádiz y su desarrollo posterior A. Martín Retortillo, S., «Aproximación histórica al tema de la descentralización», en Descentralización Administrativa y organización política, T-I, Madrid, 1973.

${ }^{6}$ Palabras del Conde de Toreno, en contestación a un Diputado en las Cortes de Cádiz de 1812 quien aludía a que si las Cortes representaban a la nación, los cabildos representaban a un pueblo determinado. Recogido de L. Morell Ocaña, El régimen local español, Civitas, Madrid, 1988, págs. 25 y ss y A. PosAdA, Evolución legislativa..., op. cit., pág. 77 y ss.
} 
to del pueblo como unidad natural, pero contenido en el Estado y subordinado a él, como expresión del interés general de la Nación «sola y única» ${ }^{7}$. En este marco, y a lo largo de todo el s. XIX (con alguna excepción relevante como la que resulta de la Revolución de 1868 y la Ley Municipal de 1870), se va consolidando la idea de los Ayuntamientos como Corporación meramente deliberante para la resolución de los asuntos «domésticos» de los pueblos bajo la tutela de la Administración suprema, reservándose a los Alcaldes —a la sazón delegados del poder central y administrador de los asuntos peculiares del municipio- todos los actos de ejecución. En síntesis, y en palabras de Colmeiro, el régimen local es un elemento subordinado a la Administración del Estado que se concibe y explica como un Poder que actúa, pero cuya naturaleza es administrativa y no política como ocurría en el antiguo régimen municipal ${ }^{8}$.

Es este marco de construcción de nuestro régimen local en el s. XIX ${ }^{9}$, en la tensión entre el reconocimiento de una autonomía a los municipios que se veía peligrosa para la unidad nacional y la concepción del poder ejecutivo que se tenía en esos momentos y el natural y permanente impulso existente en éstos para reivindicar su capacidad para la gestión de los asuntos que le eran propios ${ }^{10}$, en el que se producen las reformas al principio de este epígrafe aludidas. Y es que, en esa permanente tendencia centrífuga y centrípeta existente, la idea de un cuerpo de funcionarios (Secretarios, Contadores y Depositarios) que asegurara el respeto a la legislación, en torno a los cuales se organizara la burocracia municipal, y se evitaran corruptelas se fue consolidando de forma natural.

De esta forma, las claves de la regulación establecida a partir de mediados del s. xx descansarán en la necesidad de contar con un Secretario en todos los municipios y provincias cuyo desempeño correspondería a un funcionario de dicho Cuerpo - a salvo de los municipios inferiores a 500

\footnotetext{
${ }^{7}$ A. Posada, Evolución legislativa..., op. cit., pág. 79.

${ }^{8}$ A. Posada, Evolución legislativa..., op. cit., pág.. 207 y ss.

${ }^{9}$ De esta forma E. García de Enterría, La Administración española, Alianza Editorial, 1985, pág. 73 , podrá decir que «La construcción moderna de nuestro régimen local se efectúa rigurosamente sobre ese modelo — refiriéndose al régimen municipal francés-, del que si acaso se aparta es todavía para negar ese modestísimo ámbito de asuntos privativos propios de un pouvoir municipal originario y exclusivo, que aquí se juzga peligroso (y yo creo que el diagnóstico era certero en su tiempo) en el seno de nuestra disgregada y disgregadora sociedad; es por eso propiamente el esquema napoleónico de estricta observancia, más que su depuración posterior, el que aquí se recibe en las primeras regulaciones del s. XIX, y el que sigue vigente por de pronto hasta $1870 \mathrm{y}$ en la práctica hasta el Estatuto Municipal de 1924»

${ }^{10}$ Puede verse, coincidiendo con este análisis, el efectuado por M. BENítEZ DE Lugo, El municipio y sus elementos esenciales, Mancomunidad de Diputaciones, Madrid, 1986, págs. 25 y ss.
} 
habitantes que podrían habilitar a un vecino- y la Intervenciones de fondos y las Depositarias habrían de ser servidas por un funcionario de dichos Cuerpos cuando sus presupuestos excedieran de una determinada cuantía. A su vez, dichos Cuerpos se estructuraban en varias categorías en función del presupuesto y la población: tres categorías y doce clases en la Secretaria y seis categorías en el caso de los Interventores y Depositarios. Como régimen selectivo se establecía la oposición y se aplicaba un régimen retributivo uniforme.

Las funciones que pervivirán durante largo tiempo en el franquismo, fruto de la concepción que dicho régimen tuvo de estos Cuerpos como singular forma de control de la actividad de los entes locales (idea que como ya hemos aludido está presente permanentemente en la construcción de nuestro régimen local desde las Cortes de Cádiz), y que se perderán en su mayoría tras la aprobación de la Constitución y la aparición de las Corporaciones democráticas, se articulaban en forma tal que, en mayor o menor medida, sobre éstos Cuerpos se hacía descansar auténticamente la organización local. Puede decirse, y seguramente no se exagera, que el proceso de toma de decisiones descansaba en gran medida en estos Cuerpos y que su configuración y las funciones atribuidas a los mismos los significaban como los auténticos poderes reales o fácticos y piezas claves imprescindibles en las entidades locales cuya conformidad, desde un punto de vista legal, a las decisiones era algo casi imprescindible para la gestión de éstas ${ }^{11}$. Dicha atribución de funciones se realizaban de la siguiente forma:

- Secretarios: como miembro de la Corporación (preparar el orden del día, asistencia a sesiones, comisiones, etc...), como fedatario público (redacción y lectura del acta, certificación de todos los actos y acuerdos, etc...), como Jefe de Personal y de los Servicios Generales (adopción de disposiciones de régimen interior, dar posesión a los funcionarios de sus cargos, amonestarles, etc...), o finalmente, como Jefe directo de la Secretaría y los servicios jurídicos y administrativos.

- Interventores: quienes tenían atribuidas las funciones de fiscalización y control de la gestión económico-financiera (advertencias de

\footnotetext{
${ }^{11}$ Lo que a fuerza de ser sincero no era, ni mucho menos, una tarea grata ya que atribuciones como la advertencia de ilegalidad, subsistente desde principios de siglo, fue una permanente fuente de conflictos para el Cuerpo de Secretarios de Administración Local. Lo pone de relieve el trabajo de CARRASCo Belinchón, op.cit., págs. 15 y s., que observa que «los miembros de la Corporación consideran al Secretario, precisamente por esta obligación, no como el técnico que está para auxiliarles, sino como el vigilante enviado por el Poder Central para impedirles adoptar las decisiones que estimen procedentes».
} 
ilegalidad en relación a su función, comprobar la recepción de obras, etc...), funciones fedatarias (compulsa de documentos con obligaciones de pago), asesoría en materia económico-financiera (libros de contabilidad, redacción del anteproyecto de presupuesto, etc...) y la de Jefe inmediato de los servicios económicos y de su personal.

- Depositarios: a los que se asignaban funciones recaudatorias como Jefe de los Servicios de Recaudación y funciones de manejo de fondos (realización de pagos y cobros, arqueos, etc...)

En los extertores del franquismo la aprobación del Decreto 687/1975, de 21 de marzo y, con posterioridad, del RD 3046/77 afectará a la organización de los mismos en clases y categorías, a la exigencia de los títulos necesarios para concurrir a los procesos selectivos y se centralizarán en la Dirección General de Administración Local la aprobación de bases y programas para el acceso a estos cuerpos y la creación, clasificación, agrupación y provisión de los puestos de trabajo atribuidos a éstos.

Ello ayuda a explicar sin duda, en opinión de JIMÉNEZ AsENSIO refiriéndose a los orígenes de los Cuerpos Nacionales, que la lógica del control de legalidad sea la racionalidad dominante en un ámbito que se había caracterizado en el momento de surgir estos Cuerpos por la vulneración sistemática de la Ley. Sobre todo si se repara en que las competencias atribuidas a los municipios hasta bien entrado el siglo pasado diferían en buena medida de las funciones de prestación de servicios y del gobierno del territorio que las caracterizan en la actualidad ${ }^{12}$.

Aún más allá el déficit gerencial que nuestras entidades locales arrastran tiene asimismo que ver, al menos hasta la regulación constitucional, con esa concepción de la organización local anclada en los Cuerpos Nacionales, con unas funciones, una formación y unas obligaciones, sin duda necesarias, pero que concebidas exclusivamente de esa forma parecen lastrar una concepción distinta de la organización local. Una organización local orientada al ejercicio de potestades públicas, con unos procesos de toma de decisiones en que la garantía formal de la legalidad

\footnotetext{
12 R. JIMÉNEZ AsENSIO, «Reflexiones sobre el marco jurídico (o el corsé) de la gerencia local», en el libro colectivo Gobierno local y modelo gerencial, Estudis 4, Fundació Carles PI i Sunyer, Barcelona 1999, pág. 100 y ss. El autor refleja que, precisamente, y en la medida en que dichas funciones prestacionales se incrementan aparecerá la racionalidad gerencial en el Reglamento de Servicios de las Corporaciones Locales de 1955 con la aparición de la figura del Gerente a fin de dirigir la gestión local mediante órgano especializado, sociedad de capital íntegramente público o Organismo Autónomo y, en tiempos más cercanos, el Real Decreto 3046/1977, recogiéndolo de la legislación específica de Madrid y Barcelona, regulase los denominados Directores de Servicio.
} 
- debemos repetir por las dudas que el respeto a la legalidad nos parece imprescindible en un Estado de Derecho- será el parámetro básico, en demasiadas ocasiones el único, que habría de guiar la acción de las entidades locales.

La realidad si se es honesto con lo acontecido es que dicha situación, y a salvo de excepciones que en todos sitios pueden encontrarse, no se debió tanto a los funcionarios que componían dicho Cuerpo, sino, mucho más allá, a un modelo de organización territorial implantado por el franquismo que veía en las entidades locales no un ámbito de decisión política sobre el territorio, sino más bien una mera administración de unos cuantos servicios básicos y una esfera de control de las comunidades locales. En esta concepción autoritaria es más que lógico que se confiase a los Cuerpos Nacionales de Administración Local, aún cuando los responsables políticos fuesen designados, un control, en este caso de legalidad, de las decisiones adoptadas y un tipo de gestión burocrática de decisiones que, en su mayoría, eran adoptadas en otros ámbitos de gobierno. LEGUINA, caracterizando esta etapa, ha dicho de la misma que se produce un «uniformismo local a ultranza; neofeudalismo y corrupción generalizada por imbricación de los aparatos de poder local con los intereses económicos privados dominantes, singularmente en las grandes ciudades; centralización autoritaria y antidemocrática, ajena al más mínimo principio de legitimación popular, politización totalitaria e irresponsabilidad política de los órganos de gobierno local, sumisamente vinculados a la cadena de mando central y vaciamiento imparable de finanzas, competencias y funciones locales» ${ }^{13}$. Y Morell OCAÑA analizando el efecto de dicha situación $-\mathrm{y}$ en cierta medida la colonización del espacio político local por estos funcionarios, debemos añadir que en muchos casos por ausencia de su ejercicio- expone cómo en los inicios del régimen democrático «se puede observar con claridad que el modelo de funciones de los Cuerpos Nacionales estaba demasiado cerca de los quehaceres y problemas del Estado del s. XIX. Ese Estado quería introducirse en el control de las actividades locales mediante la sustantivación de Cuerpos de Funcionarios poseedores de esos mecanismos de control y directamente dependientes del propio Estado» ${ }^{14}$.

Pero, ciertamente y con la perspectiva que solo el tiempo proporciona, dicha situación condicionará en el régimen constitucional democrático a

\footnotetext{
13 J. Leguina Villa, Escritos sobre Autonomías Territoriales, Madrid, 1984, pág. 260.

${ }^{14}$ L. MoRell OCAÑA, «El cumplimiento de las funciones encomendadas a la habilitación nacional y la evolución de la Administración local desde 1985», trabajo incluido en la serie Documentos INAP La función pública local y la habilitación nacional, INAP, Madrid, 1995, pág. 19.
} 
dichos Cuerpos que, como ahora expondremos, habrán de enfrentarse a una injustificada, en la mayor parte de las ocasiones, desconfianza de las autoridades democráticas y a un progresivo desapoderamiento en las funciones a ellos atribuidos.

\section{Los Cuerpos Nacionales de Administración Local tras la Constitución de 1978: acentuación de la crisis de éstos e insatisfacción de los funcionarios que los sirven}

La aprobación de la Constitución de 1978 supuso, como en tantas otras cosas, un cambio radical en la concepción del régimen local. De la situación de unas entidades locales con unas funciones de mera administración del territorio, supervisadas y controladas en su actuación, ceñidas a meras actividades y servicios básicos y con una configuración no democrática, el marco constitucional abrirá nuevas perspectivas que posibilitarán, tras las primeras elecciones locales en 1979, una nueva etapa de las mismas que se insertan en el marco constitucional como un gobierno del territorio, autónomas en las decisiones adoptadas en el marco de sus intereses, de composición democrática y en las que, tras una primera etapa en que afrontar la efectiva prestación de servicios básicos a los ciudadanos se convirtió en la prioridad fundamental, se ha sucedido una segunda etapa, en la que todavía nos encontramos, y en la que la asunción de funciones propias de un gobierno del territorio, con responsabilidades en su desarrollo y promoción entre otras, han desplazado el eje vertebral de su acción abandonando definitivamente, y sin perjuicio de su sujeción a otros intereses prevalentes, el carácter de entidad subordinada y tutelada en que el mismo se situó a lo largo de dos siglos.

Sin embargo, este período no ha estado exento de conflictividad. Conflicto precisamente más acusado, en el caso de estos funcionarios que por las razones antes expresadas se convirtieron en objeto prioritario de las reformas acontecidas en el ámbito de la función pública local, y que ponían de manifiesto esa desconfianza de los nuevos responsables locales frente a los que juzgaban habían tenido un importante ámbito de decisión en los entes locales del franquismo y por la tal vez explicable necesidad de afirmar, en esos momentos, el poder democrático local frente a lo que se entendía había constituido una usurpación del espacio de gobierno local por la tecnocracia local. Como Morell Ocaña ha puesto de manifiesto, la realidad de los Cuerpos Nacionales de Administración Local en el período preconstitucional es que, emboscados tras una calificación aparentemente formal de «asesores», sin embargo eran unos auténticos «gestores» 
de nuestras entidades locales y de ahí, sigue indicando el autor citado, que la etapa democrática se caracterice por un movimiento de doble tendencia: 1) residenciar en los miembros de la Corporación las facultades de gobierno y administración de las mismas; 2) la marginación formal de los Cuerpos Nacionales, respecto de las actividades gestoras ${ }^{15}$.

Varios elementos condicionan el período y explican la sensación de pérdida de peso relativo de estos Cuerpos Nacionales y la que podríamos llamar crisis en que se han desenvuelto, en ocasiones, sin disimuladas apelaciones a su desaparición inclusive compartidas en algún sector de la doctrina científica ${ }^{16}$.

La celebración de las primeras elecciones democráticas y la toma de posesión de los primeros electos locales se tradujo, aprovechando la primera reforma del régimen local hasta entonces vigente propiciada por diversas sentencias del Tribunal Constitucional sobre el régimen local (STC 4/1981, 14/1981), en la desaparición de la advertencia de ilegalidad atribuida hasta esos momentos a los Cuerpos Nacionales de Administración Local y que se juzgaba un importante instrumento de poder de estos funcionarios tras el Real Decreto Ley 3/1981, de 16 de enero y, posteriormente, con la Ley 40/1981, de 28 de octubre (aunque, ciertamente, y con posterioridad resurgirá la misma con la legislación hacendística local para la función interventora).

Pero esto sólo era un primer paso. Las reticencias sobre estos funcionarios, a pesar de haberles suprimido tan importante instrumento de control, continuaban y el desarrollo del régimen local constitucional a través de la Ley 7/1985, de 2 de abril, Reguladora de las Bases de Régimen Local y del RD Legislativo 781/1986, de 18 de abril, por el que se aprobaba el Texto Refundido de las Disposiciones Legales Vigentes en materia de régimen local consagrarán la desarticulación de estos funcionarios, eufemísticamente denominados a partir de entonces funcionarios con habilitación de carácter nacional, y la intención nunca formalmente declarada de despojarlos de la mayoría de sus funciones sobre todo en lo que a los Secretarios de Administración Local se refiere ${ }^{17}$.

\footnotetext{
${ }^{15}$ L. Morell OCaña, «El cumplimiento de las funciones..., op. cit., págs. 18 y 19.

${ }^{16}$ Véase, a este respecto, R. JimÉnez AsEnsio, «Reflexiones sobre el marco jurídico...», op. cit., pág. 118.

${ }^{17}$ Un estudio muy preciso del régimen jurídico que afectó a estos funcionarios tras la aprobación de las reformas de régimen local puede encontrarse en J. D’AnJou González, «El Estatuto Peculiar de los funcionarios con habilitación de carácter nacional», El Consultor de los Ayuntamientos y los Juzgados, $\mathrm{n}^{\circ} 15 / 16,1989$. Con posterioridad, y tras las sucesivas reformas del régimen jurí-
} 
En efecto, la legislación de régimen local de los años ochenta se orienta a reforzar a los electos locales, específicamente al Alcalde, frente a estos funcionarios $\mathrm{y}$, consecuentemente, realiza dos operaciones:

- Atribuir a éste, sin perjuicio de la delegación que el mismo realice en otros corporativos, la dirección de personal, la dirección de los servicios administrativos $\mathrm{y}$, en general, todas aquellas funciones ejecutivas, de coordinación y directivas que a los Secretarios les estaban atribuidas en la anterior legislación de régimen local y a las que anteriormente nos referíamos.

- Simultáneamente, y en correspondencia con lo anterior, definir el núcleo de funciones de la Secretaria ceñidas a dos competencias específicas: la fe pública y el denominado asesoramiento legal preceptivo que, como es sabido, es algo mucho más reducido que la función de asesoramiento jurídico y que finalmente los configuraba como un órgano staff alejado de funciones gestoras que, en otro momento y ya lo hemos visto, eran un núcleo importante en su función y que sólo se conservaron, al amparo de los dispuesto en el artículo 166 TRRL, en aquellos supuestos en que el prestigio o la confianza que el equipo de gobierno tenía en el funcionario en concreto ameritaron su mantenimiento ${ }^{18}$.

El resultado y la consecuencia al mismo tiempo de este proceso ha sido instalar en este grupo de funcionarios, que se quiera o no, posee una excepcional preparación y formación un sentimiento de desconfianza, e inclusive de persecución, que se refleja en los múltiples trabajos y colaboraciones que muchos de ellos realizan en distintas revistas dedicadas al mundo local. Y es que, en efecto, basta repasar El Consultor de los Ayuntamientos o la Revista de Estudios Locales, revistas como se sabe especializadas en el mundo local, para observar dicha situación en los múltiples trabajos que sobre su situación profesional pueden encontrarse.

\footnotetext{
dico de éstos, puede verse el trabajo del mismo autor «La nueva regulación sobre provisión de puestos de trabajo reservados a funcionarios con habilitación de carácter nacional», El Consultor de los Ayuntamientos y los Juzgados, no 22, 1993.

${ }^{18}$ Funciones que se desarrollan en los artículos 2 y 3 del RD 1174/1987, de 18 de septiembre y que limitan, de forma importante, la función de Secretaria con respecto a la funciones contempladas con anterioridad. Ciertamente, el artículo 166 del RD Legislativo 781/1986, de 18 de abril dejaba la puerta abierta a la asignación de otras funciones distintas o complementarias remitiéndose para ello a las relaciones de puestos de trabajo de la entidad. Piénsese, a estos efectos, la dificultad de ceñir a dichas funciones el papel que dichos funcionarios desempeñan en los ayuntamientos pequeños (la mayoría como se ha expuesto) donde, se quiera o no, son la unidad fiscalizadora, gestora y asesora.
} 
Sin embargo, la desconfianza sobre este grupo de funcionarios no cedió a pesar de las reformas realizadas $y$, fruto de la necesidad sentida principalmente en grandes corporaciones de que el criterio de la confianza presidiese la elección de cualquier funcionario directivo de la entidad, a principios de los noventa se introducirá, de forma contradictoria con las funciones a desarrollar (asesoramiento legal a la Corporación, control y fiscalización de las cuentas, recaudación, manejo de fondos y valores, etc...), el procedimiento de libre designación para la provisión de las plazas vacantes, bien es cierto que limitado a ciertos supuestos aunque la propia dinámica de las cosas ha ido extendiendo progresivamente el sistema ${ }^{19}$. Bien es cierto que, en primer término, el Tribunal Supremo (STS de 3 de enero de 1996, Ar. 2769) y, con posterioridad, el Tribunal Constitucional (STC 235/2000, de 5 de octubre) confirmaron, a mi juicio equívocamente con las funciones a desarrollar, la constitucionalidad del sistema ${ }^{20}$.

${ }^{19}$ En efecto, la Ley 31/1991, de Presupuestos Generales del Estado ya introdujo la libre designación como fórmula a utilizar para la provisión de estos puestos de trabajo. Con posterioridad, la Ley 10/1993, de 21 de abril regulará definitivamente dicho sistema que será objeto de desarrollo por el RD 731/1993, de 14 de mayo y, con posterioridad,, por los artículos 27 a 29 del Real Decreto 1732/1994, de 29 de julio y que han sido recientemente modificados por el RD 834/2003, de 27 de junio que finalmente, junto al aspecto comentado, ha dado solución a una sinrazón histórica consistente en considerar que las funciones de Secretaria-Intervención por el hecho de ser desarrolladas en municipios de menor número de habitantes tienen menos complejidad o dificultad técnica. Dicha regulación contempla la posibilidad de la libre designación, como mecanismo excepcional (lo que francamente no ha sido cumplido dada su progresiva implantación en todos los municipios que cumplen los criterios establecidos) siempre que se cumplan dos tipos de requisitos: unos atinentes al tipo de Corporación, según población, presupuestos y características de la misma; otros, relativos al puesto, que dicho puesto de trabajo tenga establecido nivel 30 de complemento de destino y que comporte un «marcado» carácter directivo de sus funciones o una especial responsabilidad en la función a asumir. En torno a esta última reforma puede verse el comentario de A. Martínez Marín, «La reforma 2003 de los funcionarios locales con habilitación estatal», Revista de Estudios de Administración Local, nº 291, págs. 649 y ss.

${ }^{20}$ Es importante resaltar, sin embargo, que la sentencia STC 235/2000 recibió numerosas críticas, empezando por el voto particular que cuestionó, hemos de decir que con bastante lógica, que dicho sistema permitiese garantizar el principio de imparcialidad en el ejercicio de la función no siendo, a estos efectos, las garantías suplementarias contenidas en los preceptos enjuiciados. Bien es cierto que, al menos parcialmente ya que a nuestro juicio en el tipo de funciones enjuiciadas el procedimiento de libre designación es inapropiado, la reciente modificación del artículo 28 y 29 por el RD 834/2000 amplía las garantías de estos funcionarios ya que: de una parte, los funcionarios cesados y el desempeño de los puestos de trabajo que se les garantizan en caso de cese no es hasta que consigan otros por los procedimientos establecidos en la normativa; $y$, de otra, específicamente se establecen garantías retributivas en relación a qué complemento de destino han de tener dichos puestos y las funciones que ya no podrán ser otras que las relativas a un puesto de trabajo de su subescala y categoría. Sin embargo, ello nos lleva a otro tipo de problemas: ¿se producirá un incremento progresivo sin ser necesarios de los FHCN sin otro criterio que el haber sido cesados por motivos de confianza? ¿De verdad, con estas componendas, se garantiza la profesionalidad y la imparcialidad en el ejercicio de la función o se prima el interés político a corto plazo? Cabe destacar algunos comentarios sobre esta problemática como el de G. MESA BRIOSO, «Funciones direc- 
Por otro lado, la jurisprudencia del Tribunal Constitucional ha sido francamente decepcionante para este colectivo. En unos casos, como en el supuesto de la STC 25/1983, de 7 de abril, con declaraciones como básico de materias ciertamente discutibles respecto de los funcionarios con habilitación de carácter nacional $-\mathrm{y}$ algo ancladas en una visión preconstitucional de la problemática planteada - que con posterioridad han sido objeto de matización normativa permitiendo la participación de las Comunidades Autónomas y las entidades locales ${ }^{21}$, y en otros, como en el de la libre designación comentada, no preservando el principio de imparcialidad en relación a la función desarrollada (STC 235/2000. de 5 de octubre) ${ }^{22}$.

Todo ello desembocó a finales de los noventa en una situación que puede calificarse, sin riesgo a equivocarse, como insatisfactoria para todos los interesados. Salanova Alcalde lo ponía de manifiesto indicando que ni las entidades locales (que desean mayor autonomía en la designación de su personal y que invocan la necesidad de una relación de confianza dada la importancia de las funciones desempeñadas), pero ni los funcionarios incluidos en las Escalas de habilitación nacional que padecen una serie de disfunciones (inseguridad en la periodicidad de convocatorias, el célebre peregrinaje del primer destino en su calidad de aspirantes, las prácticas viciadas en la fijación de méritos específicos a efectos de concursos, la

tivas, especial responsabilidad y garantías suplementarias de la libre designación de los funcionarios con habilitación de carácter nacional: Breve comentario crítico de la STC n 235/2000», Revista de Estudios Locales, $\mathrm{n}^{\circ}$ 46, 2001. Más recientemente, con una reflexión sobre la objetividad y imparcialidad e independencia que requieren dichas funciones es de destacar el trabajo de A. SÁNCHEZ BlANCO, «La función pública de los Secretarios e Interventores de la Administración Local», Revista de Estudios de Administración Local, nº 291, págs. 1025 y ss.

${ }^{21}$ Muy crítico con los razonamientos seguidos se muestra AgirRezcuenaga, op. cit., págs. 99 y ss. Asimismo, puede verse J. Esteve PARDo, «Bases estatales y competencias de ejecución», REDA n ${ }^{\circ}$ 39, 1983, pág. 620. Efectivamente, y con posterioridad fruto de las presiones políticas de las entidades locales y las Comunidades Autónomas, se ha reconocido la participación de éstas. En este sentido, la Ley 10/1993, de 29 de diciembre, introdujo tanto el procedimiento de libre designación como las facultades decisorias de los entes locales en los concursos y la Ley 22/1993, de 29 de diciembre, incrementó las competencias de las Comunidades Autónomas, de un lado, atribuyéndoles la posibilidad de fijar un 10 por 100 del total de los méritos de los concursos y, de otro, fijando como competencias de ejecución de éstas en materia de clasificación de puestos de trabajo, nombramientos provisionales, comisiones de servicios, acumulaciones y permutas. Y, con posterioridad, la Ley 42/1994, de 30 de diciembre, atribuyó a las Comunidades Autónomas la competencia sobre nombramientos de interinos.

${ }^{22}$ Curiosamente, y paradojas de la jurisprudencia, el sistema de terna entre los tres aspirantes con mayor puntuación, vigente con anterioridad al Concurso de méritos actualmente establecido, fue declarado por la STC 193/1987, de 9 de diciembre, como contrario a los principios de mérito y capacidad declarando que no guardaba relación alguna con el principio de autonomía local. 
arbitrariedad retributiva y la desnaturalización del procedimiento de libre designación) parecen encontrarse cómodos en el sistema ${ }^{23}$.

En cualquier caso, la solución a esta situación no pasa por la simple y expedita fórmula de suprimir dichos Cuerpos, sin ni siquiera una reflexión previa, o por la minoración de las garantías para un adecuado ejercicio de la función de control y fe pública que desarrollan estos Cuerpos en los Gobiernos locales. Las cosas son más complejas. Y como ya ha advertido RAMIO se corre, con este tipo de improvisación tan al uso, un riesgo grave de desistitucionalización de nuestras entidades locales ${ }^{24}$.

\section{LOS CAMBIOS QUE SE HAN PRODUCIDO EN EL ENTORNO DE NUESTRAS ENTIDADES LOCALES Y EN LA FORMA DEL GOBIERNO LOCAL COMO CLAVES PARA REDEFINIR A LOS CUERPOS NACIONALES DE ADMINISTRACION LOCAL}

\section{Breve alusión a los elementos que condicionan al régimen local español}

Ya nos hemos referido a que el sistema de función pública local, la distribución de funciones dentro de la misma y, en su caso, la reserva de éstas a favor de un determinado colectivo de funcionarios ha de guardar una necesaria armonía con la organización local en que se inserta y, en última instancia, con el modelo o forma de Gobierno local que existe en nuestro país. Y éste, ya nos hemos referido a ello, se ha transformado significativamente desde la aprobación del texto constitucional.

Y cuando nos referimos a este punto es preciso reseñar también, y en primer lugar, los elementos fácticos que condicionan este sistema de Gobierno local. Por de pronto habremos de aludir a una circunstancia que

\footnotetext{
${ }^{23}$ R. Salanova AlCALDE, «La provisión de puestos y la Autonomía Local», trabajo incluido en la serie Documentos INAP La función pública local y la habilitación nacional, INAP, Madrid, 1995, págs. 37 y ss.

${ }^{24}$ C. RAMIO, «Los habilitados en la era del management. Modernizarse profesionalmente para evitar la desinstitucionalización de las Administraciones locales». Conferencia pronunciada en la Conferencia 2003 del COSITAL, Puerto de Santa María y donde pone de manifiesto que tres estrategias están provocando dicho fenómeno: la primera de ellas consistente en la transformación de facto del modelo histórico de función pública; en segundo lugar, el haberse instalado, sin matices, una cultura empresarial de la gestión pública local; por último, la externalización de una parte importante de los servicios públicos locales.
} 
condiciona muchas de las reflexiones que podamos realizar sobre éste y que, sin duda, está en la base de decisiones muy relevantes sobre el mismo y que no es otra que el nuevo escenario en que se desenvuelven el conjunto de las organizaciones municipales y supramunicipales en nuestro país ${ }^{25}$.

Me consta, ciertamente, que resulta recurrente referirse a ciertas causas que condicionan el panorama actual en que se desenvuelve el gobierno local $^{26}$. Recurrente pero necesario para entender los cambios que se han producido en los últimos años. Entre otras muchas que podríamos enumerar cabe señalar, a los efectos que nos proponemos, algunas de éstas: creciente liberalización de los mercados y el consecuente aumento del peso de las empresas multinacionales; el aumento de la competencia entre empresas y de la competencia indirecta en el mercado laboral mundial; surgimiento de instancias supranacionales e influencia creciente de los organismos financieros internacionales, etc... De esta forma, la incapacidad del Estado para regular los movimientos financieros limita enormemente su margen de maniobra para atraer inversiones a través de las políticas fiscal y arancelaria. La movilidad del capital no depende de las tradicionales ventajas comparativas analizadas en el comercio internacional. Ni los recursos naturales, ni la situación geográfica constituyen hoy inequívocas ventajas comparativas. Hoy el capital se globaliza, aunque el trabajo se localiza.

En síntesis, este conjunto de causas ha producido una cierta transformación de las circunstancias en que se desenvolvían tradicionalmente las relaciones entre las entidades estatales y subestatales que se han traducido en un nuevo esquema de relaciones en el ejercicio del gobierno del territorio. A saber: a) La generación de una nueva relación entre el Estado Nacional y las administraciones subregionales y municipales en que estos últimos son los principales actores del desarrollo; b) Los procesos de inte-

\footnotetext{
${ }^{25}$ Sobre el conjunto de la problemática es muy relevante la opinión de los partidos políticos de ámbito nacional más relevantes recogida en el volumen colectivo Problemas actuales de la Administración Local, Colex, Madrid, 2002, y en el que se recogen las opiniones de PSOE, PP y IU sobre los retos a los que han de enfrentarse los municipios en este momento.

${ }^{26}$ Hay una interesante bibliografía sobre la influencia de estos cambios en las entidades locales. A título de ejemplo destaquemos J. BoRJA, y M. CASTELL, Local y Global. La gestión de las ciudades en la era de la información, Taurus, Madrid, 1997; J.M. PASCuAl y Esteve, La estrategia de las ciudades, Diputación de Barcelona, Barcelona, 1999; M. Forn I FoxA, «Planificación estratégica y desarrollo económico», en el volumen Las grandes ciudades: debates y propuestas, Economistas Libros, Madrid, 1991; M. Porter, La ventaja competitiva de las naciones, Plaza y Janés, Barcelona, 1992; D.L. Sorkin, y otros, Strategies for Cities and Countries, Public Technology Inc., 1987.
} 
gración regional exigen que la planificación del desarrollo se desarrolle bajo parámetros distintos y más amplios; c) Un mundo más global que genera lo que se ha dado en llamar una nueva geografía de poder en que la competitividad viene ligada a cuestiones territoriales y en que el incremento de la competencia se produce entre territorios (no necesariamente naciones), y especialmente entre sus puntos nodales: las ciudades ${ }^{27}$.

Por ello, en esta nueva etapa en la que la economía global se materializa en una red transfronteriza de regiones y ciudades estratégicas y en las que se integran no solo grandes ciudades, sino, también, ciudades medias, el escenario político tiene nuevos actores, a partir de las regiones y las ciudades ${ }^{28}$. Y esto nos lleva, de forma obligada, a la necesidad de replantear las relaciones tradicionales entre el Estado-Nación y las unidades subestatales que se manifiesta en varios sentidos: el primero de ellos, ya clásico y suficientemente analizado por la doctrina científica, en el desbordamiento del primero que ha impulsado de forma creciente los procesos de descentralización del ejercicio del poder (con pérdidas de soberanía instrumental en marcos más amplios y con una crisis en su gestión pública en el interior que le priva de asignar eficiente y equitativamente sus recursos); en segundo término, la aparición de nuevos actores públicos y privados que obligan a replantear las funciones de intervención y toma de decisiones tradicionales; por último, y en tercer lugar, con una ampliación de las funciones tradicionales de los entes locales que ya no tienen un horizonte prefijado de antemano, sino que han de constituirse en actores de su propio desarrollo generando estrategias de desarrollo y promoción económica local tendentes a proyectarse externamente y generar ventajas competitivas territoriales.

De esta forma, la competitividad internacional de un país va a estar determinada en gran medida por la productividad y la capacidad de innovación de sus áreas de aglomeración económica. Las áreas urbanas funcionan así como centros de alto rendimiento económico que determinan que la globalización no implique una pérdida del papel de lo local que, por el contrario, se ve fortalecido en la medida en que se potencia la integración territorial de actividades y en que las ciudades son parte de un sistema de centros que compiten por la radicación de factores económicos ${ }^{29}$.

\footnotetext{
27 Véase al respecto el trabajo de M. Del Huerto Romero, O. Madorey, «Ciudades y Regiones frente a las transformaciones globales», GAPP, $\mathrm{n}^{\circ} 10,1997$, págs 115 y ss.

${ }^{28}$ J. BorJa. La internacionalización de las ciudades, en Revista Córdoba, Ciudad y desarrollo, $\mathrm{n}^{\circ} 9$.

${ }^{29}$ En torno al papel de las ciudades en la globalización puede consultarse el trabajo de S. SASSEN, Las ciudades en la economía global, Editores ROJAS y DAUGHTERS, BID, Washington, 1998.
} 
Las ciudades, de este modo, han de competir, al menos, en tres dimensiones diferentes generando para ello infraestructura urbana y social:

a) La competencia por el potencial productivo: es decir mejorar su posición competitiva dentro de la división internacional del trabajo por medio del fomento a la radicación o expansión de complejos productivos o de empresas fuertes y competitivas en el ámbito internacional.

b) La competencia por el potencial de consumo: las ciudades $-\mathrm{y}$ los municipios menores dentro de áreas metropolitanas - intentan mejorar su competitividad atrayendo a estratos de alto poder adquisitivo y, por ello, con mayor capacidad de compra.

c) La competencia por las funciones de conducción económica: es decir, mejorando su competitividad por medio del asentamiento de las funciones económicas y políticas claves tales cómo: 1) desarrollo de una infraestructura de comunicación y transportes adecuada; 2) ampliación de la oferta disponible de suelo y edificios adecuados para las instalaciones productivas.

En resumen, y como han puesto de manifiesto MAGRE y BERTHANA, estamos ante un «nuevo localismo» en el que las instituciones locales se refuerzan, con un contenido político y no meramente administrativo, por variados motivos: por la capacidad demostrada por los municipios para hacer frente a los procesos de mundialización; por la importancia de la identidad cultural de lo que es local en estos procesos; y, por último, indican los citados autores, por las posibilidades de desarrollar procesos de índole democratizadora a través de la participación activa de los ciudadanos ${ }^{30}$.

Elementos a los que hay que unir, como ha señalado Ramió, que nos encontramos frente a un importante proceso de cambio - similar en importancia al que se experimentó en los años veinte del siglo xx cuando el sector público en España se multiplicó por tres apostando por la intervención económica o en los años ochenta cuando el sector público se duplicó al diseñarse un Estado del bienestar descentralizado a nivel político y administrativo - gradual pero muy relevante que consiste en la acomodación institucional y de gestión de nuestras Administraciones públicas, inspirado

\footnotetext{
30 J. Magre Ferrán, y X. Bertrana Horta, «El Alcalde como líder político y ejecutivo en los países de la Unión Europea», Revista de Estudios Locales, número extraordinario, julio 2003, pág. 69, con cita de C. NAvarro, C., «Límites al nuevo localismo: Gobierno municipal de las democracias occidentales en perspectiva comparada», Revista de Estudios Políticos, nº 100, 1998
} 
por la denominada «Nueva Gestión Pública», a un modelo de Estado del Bienestar condicionado por unos limitados recursos económicos ${ }^{31}$.

Este cúmulo de circunstancias, que finalmente han de repercutir en las decisiones que se adopten y que sin duda han de transformar los parámetros de acción y decisión en que se desenvuelven nuestros Gobiernos locales, nos introducen en la necesidad de una nueva Gobernanza local que Alli Aranguren ha caracterizado en una serie de elementos presentes en ésta y a la que los gobiernos locales han de dar respuesta: a) un escenario de muchos participantes en que los problemas colectivos sólo pueden ser resueltos por los poderes públicos con la cooperación de otros protagonistas por medio de fórmulas de participación, colaboración, mediación, arbitraje y autorregulación que hacen más eficaz y legítima la acción pública; b) regulación por regla formales e informales que han sido elaboradas de modo participativo por los implicados en su posterior aplicación y evaluación, que la dotan de legalidad; c) utilización de las estructuras sociales, de las redes de cooperación y los mecanismos de mercado y del management para la mayor eficacia de la gestión; d) funcionamiento con lógica de medios-fines, aportaciones-resultados, eficacia y eficiencia, y con otras más fundadas en los valores de la ética democrática, como la transparencia, la integridad, la honestidad, la responsabilidad, la confianza social, la igualdad, etc.; toma de decisiones políticas por agentes políticos y en marcos políticos, no solamente por gestores y tecnócratas ${ }^{32}$.

Y la articulación de esta nueva gobernanza que necesitan nuestros municipios, y por las exigencias de cooperación que comporta, nos llevan inexcusablemente a la reflexión sobre la estructura municipal en nuestro país y si la ordenación de ésta se corresponde, asimismo, con esos nuevos retos que se plantean. Me refiero concretamente a la enorme heterogeneidad y al elevado número de entidades locales en nuestro país, y con ello a la existencia, asimismo de forma variable según la Comunidad Autónoma a la que nos refiramos, de una estructura municipal débil, excesivamente segregada ${ }^{33}$, y con escasa capacidad de recursos financieros, humanos y

\footnotetext{
${ }^{31}$ C. RAmIO, «Diagnóstico y propuestas sobre la innovación institucional y de gestión de las Administraciones Locales», Revista de Estudios Locales, número extraordinario, julio 2003, pág. 127.

32 J. Alli Aranguren, J., «La gobernanza local», Revista de Estudios de Administración Local, n ${ }^{\circ}$ 291, pág. 67.

${ }^{33}$ Aproximadamente, a principios del año 2000, existían según el INE en nuestro país 8.104 municipios, de los cuales sólo 293 tenían una población que superaba los 20.000 habitantes, unos 853 se situaban en el tramo existente entre 5.001 y 20.000 habitantes y el resto, nada menos que 6.958 municipios, eran inferiores a ese número. Casi cinco mil municipios, abundando en lo expuesto, eran inferiores a 1.000 habitantes.
} 
técnicos. Y respecto de la que es difícil, podría decirse que imposible, aplicar las consideraciones que se han realizado en los párrafos anteriores, inclusive poder afirmar en estos casos los rasgos identitarios de una esfera de gobierno ${ }^{34}$.

La consecuencia a esta problemática no ha podido ser otra que la agrupación municipal voluntaria para la prestación de determinados servicios. De esta forma, el incremento de mancomunidades para la prestación de servicios ha sido un proceso en constante aumento ya sea para un servicio concreto (461 a finales de 1998) o para fines múltiples (448 en el mismo período). Y es que es preciso, en esta era de la globalización, encontrar lo que Dromi ha llamado el «límite de la instancia a escala» y que explica en el hecho de que tanto las micro como las macrociudades se parecen por ser extremos de exclusión, en el primer caso, o de falta de acceso, en el segundo ${ }^{35}$.

Conviven en nuestro sistema local, por ello, organizaciones de gran complejidad y con capacidades importantes a la hora de gestionar la prestación de servicios a los ciudadanos, con otras que básicamente subsisten - perviven o malviven si se quiere llamarlo así- condicionadas a las subvenciones y aportaciones de otras Administraciones territoriales y que se caracterizan, en suma, por una escasa capacidad para hacer frente a los retos y desafíos que el gobierno del territorio y la prestación de servicios públicos plantea en el momento actual. Es por esta causa por lo que se ha dicho, y con razón, que nuestro régimen local tiene una geometría variable, no uniforme, y como consecuencia de dicha afirmación extraer la natural consecuencia de que difícilmente son extrapolables las soluciones organizativas, de redistribución de competencias y de misiones sobre el territorio a todos los municipios. Inclusive, entre municipios del mismo nivel, podemos encontrar singularidades importantes derivadas de factores geográficos o poblacionales (municipios turísticos, de montaña, metropolitanos, etc...) que exigen un enfoque diferente respecto de sus competencias, capacidades y recursos porque diferentes, sencillamente, son sus circunstancias. Y todo ello aún cuando nuestro régimen local se ha carac-

\footnotetext{
${ }^{34}$ Véase, en torno a este punto, la opinión de R. PARADA VÁzQUEZ, en el volumen colectivo ya citado Problemas actuales..., págs. 63 y ss.

${ }^{35}$ R. Dromi, «La vida local y los límites naturales de la globalización», Revista de Estudios de Administración Local, $\mathrm{n}^{\circ} 291$, pág. 322 y ss. Indica dicho autor que en las macrociudades falta de todo y las macro se caracterizan por ser cárceles de acero y vidrio que monopolizan el poder a un costo de contaminación, de inseguridad y stress que no es fácil para el hombre dominar a esta altura de la definición del perímetro ideal de la ciudad. Por ello, de un lado, las pequeñas ciudades se agrupan en mancomunidades y las grandes ciudades se dividen en distritos, barrios, etc...
} 
terizado tradicionalmente por el principio de uniformismo y éste comienza a presentar sus déficit ${ }^{36}$.

Es preciso, en suma, y si como parece no es posible abordar una racionalización más decidida del mapa municipal, deslindar de forma precisa lo que pueda significar la representación de los intereses de las comunidades locales con la efectiva atribución a éstas de competencia para la prestación de los servicios urbanos, ambientales, de promoción y desarrollo del territorio, etc... que hoy demanda una sociedad competitiva y en pleno desarrollo como la sociedad española. Este principio de diversidad, además, ha de plasmarse por tanto no sólo en el régimen organizativo como ha acontecido en la Ley de Modernización del Gobierno Local, sino también, y me parece al menos igual de relevante, en el esquema competencial ${ }^{37}$

Añádase a ello que los procesos urbanos y territoriales en marcha ponen en crisis una organización basada, en forma exclusiva, en los límites administrativos de carácter territorial — cuestión de otro lado que en lo que respecta a la articulación supramunicipal y el papel de la provincia es aún una cuestión no resuelta - y es preciso conjugar dicha fórmula tradicional con los límites funcionales que se presentan tanto en cuanto a la prestación de los servicios municipales como en la estrategia de desarrollo a que se ha hecho anteriormente referencia.

Abundando en la complejidad que presenta el mundo local de hoy se pueden subrayar otras circunstancias derivadas de esta última reflexión que han de estar en la base de cualquier discusión o propuesta que pretenda abordar con soluciones realistas los retos que presenta la adecuada estructuración del Gobierno del territorio, a saber: la existencia de realidades urbanas integradas por varios términos municipales y que crean una problemática urbana común; las infraestructuras de transporte terrestre que facilitan la movilidad y la residencia en lugares distintos; las dinámicas ambientales derivadas de la existencia de espacios naturales y que exigen un tratamiento conjunto más allá de los límites municipales o provinciales; las nuevas necesidades que la sociedad en materia de ocio y consumo plantea; o, por poner un último ejemplo, las necesidades asimé-

\footnotetext{
${ }^{36}$ Véase, en torno a este punto, T. FonT I LLOVET, «La evolución del gobierno local en España: de nos nuevos principios a la geometría variable», Anuario de Gobierno Local 1999/2000, Marcial Pons, 2000 y en el que se reclama que se atienda a la diversidad que presentan los gobiernos locales en la actualidad.

${ }^{37}$ En el mismo sentido puede verse el trabajo de J.L. Morillo-Velarde Pérez, «Ante la reforma del Régimen Local», Revista de Estudios de Administración Local, n² 291, pág. 738 y 747 y ss..
} 
tricas en relación a su dimensión geográfica y humana que plantean la prestación de ciertos servicios públicos (agua, residuos, transportes, etc...).

En suma, y como ha destacado algún autor ${ }^{38}$, complejidad creciente (social, económica, normativa, funcional, etc...) y demandas en la prestación de servicios que ha de tener su necesario reflejo en la formas de organización administrativa y en las formas de articular nuestro gobierno y nuestra burocracia local.

Pero hemos aludido a que también se ha experimentado importantes cambios en la forma del Gobierno local. Por de pronto, se quiera o no y a pesar de las autorizadas discrepancias doctrinales (GARRIDO FALLA, EnTRENA Cuesta, etc...), la dimensión política de éste y no meramente administrativa derivada tanto de la composición democrática de sus órganos como de la labor de dirección política que ejercen sobre el conjunto de los intereses que concurren en el territorio, según la propia definición contenida constitucionalmente en el artículo $137 \mathrm{CE}$ y la cláusula general establecida en el artículo 5 LRBRL, y no simplemente sobre una parte de ellos y que, además, ha llevado a Morillo-Velarde Pérez, a la vista de los cambios acontecidos, a reclamar decididamente el fortalecimiento de la cláusula general de competencia a favor de los entes locales o, al menos, a una parte de ellos ${ }^{39}$. De una Administración local, de fuerte inspiración francesa como veíamos, construida sobre la noción de «Corporaciones» locales, caracterizada por el uniformismo, y con un sistema orgánico-funcional en que el poder ejecutivo era compartido por varios órganos municipales, transitamos, hace ya algunos años ${ }^{40}$, hacia un sistema o forma de Gobierno local de corte más decisivamente parlamentario y en el que, habremos de reconocerlo, la inexistencia de un modelo claro hacia el que encaminarnos ha determinado algunas vacilaciones. En un primer momento, en concreto con la reforma acontecida en $1999^{41}$, dirigirnos hacia un decidido fortalecimiento de la figura del Alcalde, que se mantiene respecto de los municipios de régimen común, y con la reforma operada en 2003 hacía una aparente derivación de sus funciones ejecutivas y

\footnotetext{
38 J.M. RodRíGuEZ ÁLVAREZ, «La política de selección de los funcionarios de Administración local con habilitación de carácter nacional», GAPP n 16, 1999, págs. 133 y ss.

${ }^{39}$ J.I. Morillo-Velarde, op. cit., págs. 737 y 748.

${ }^{40}$ De ineludible referencia en este punto resulta el trabajo de R. JIMÉnEZ AsENSIO, «La forma de gobierno local: ¿cambio o continuidad?, Anuario del Gobierno Local 1999/2000, Marcial Pons/Instituto de Derecho Público, Madrid, 2001, págs. 137 y ss.

${ }^{41}$ Sobre el sentido y alcance de esta reforma en relación al Alcalde puede consultarse mi trabajo «La configuracion de los organos unipersonales en la reforma del régimen local». Revista de Estudios de la Administración Local y Autonómica nº 280-281, 1999, págs 313-353.
} 
administrativas a favor de un órgano colegiado, la Junta de Gobierno, que aparentemente habrá de asumir las mismas. Lo relevante, en cualquier caso, y a los efectos expositivos que perseguimos, es poner de relieve que, se coincida o no con dicho planteamiento y se suscriban o no las medidas adoptadas, el sistema organizativo-funcional del Gobierno local se ha transformado sustancialmente en los últimos años. Y si la organización ha sufrido tan importante transformación habremos de preguntarnos también por las transformaciones que la función burocrática debiera afrontar, sobre el sentido y alcance que pueden tener en la actualidad la existencia de unos funcionarios con una relación orgánica dependiente del Estado, sobre las garantías que las funciones que ejercen deben de tener para poder ser llevadas a cabo, por su inserción o no como una función directiva, etc...

\section{Las carencias del sistema de dirección política y de función directiva: su incidencia en los funcionarios con habilitación de carácter nacional}

Con mayor o menor unanimidad, y a salvo de las complejas soluciones que se arbitren para dar respuesta a los problemas enunciados en el apartado anterior y que excederían de la finalidad de este trabajo, puede coincidirse en que las nuevas circunstancias en que se desenvuelven nuestras entidades locales precisan de un liderazgo político y una función directiva que difícilmente puede desenvolverse en los parámetros y marcos jurídicos que existían en el inicio en nuestro país del gobierno local democrático ${ }^{42}$.

Simplemente, ni las necesidades hoy son tan evidentes en las comunidades locales como lo eran en aquél momento, ni las exigencias en términos de resultados de las políticas locales eran como hoy tan inexcusables, ni las formas y los procedimientos en la producción de políticas revestían la misma complejidad.

Tampoco parece probable que los eventuales modelos y esquemas a implementar sean reconducibles a la unidad porque diversos son los frentes en que se desenvuelve la acción local. Por de pronto, y en atención a las distintas cuestiones planteadas en el apartado anterior, difícilmente

\footnotetext{
${ }^{42}$ Puede verse, a estos efectos, y por su reciente aparición, el conjunto de trabajos incluidos en el número extraordinario de la Revista de Estudios Locales de julio de 2003 sobre la Función Directiva y la Administración Local. Con anterioridad, amén de diversos trabajos que también ponen de manifiesto dicho fenómeno, los distintos trabajos contenidos en el volumen Gobierno Local y modelo gerencial, Estudis 4, Fundació Carles PI i Sunyer, Barcelona, 1999.
} 
puede mantenerse el todavía vigente esquema de articulación entre el gobierno y la administración de nuestros gobiernos locales pensado bajo otros paradigmas y otras funciones de éstos, y mucho menos, a la vista de las presentes circunstancias, puede anclarse en un planteamiento sólo y exclusivamente ligado al cumplimiento formal del principio de legalidad que era la auténtica preocupación cuando se produce el fortalecimiento de estos Cuerpos a principios del siglo pasado. Es decir, los problemas planteados exigen, como no puede ser menos en un Estado de Derecho, el respeto escrupuloso de las reglas derivadas de éste. Pero esto no basta. Ni la prestación de servicios que demandan nuestros ciudadanos, ni la articulación de políticas en términos de resultados y exigencia de responsabilidad, ni las exigencias que plantea la adopción de una estrategia competitiva y de desarrollo del territorio pueden satisfacerse sin más con el cumplimiento de las formas y procedimientos legales y es preciso cohonestar estas exigencias, ineludibles y necesarios para las Administraciones públicas en un Estado de Derecho, con otras que radican en la base de la definición de gobernanza y que se han reflejado, específicamente en el ámbito europeo, en el Libro Blanco para la Reforma de la Comisión o el Libro Blanco sobre la Gobernanza Europea.

Y ello parece aconsejar, como se viene reivindicando de forma constante en los últimos años, replantear bajo otros esquemas el ejercicio de la acción de gobierno y la función directiva en las entidades locales. Transformar un ejercicio de la función ejecutiva y administrativa de éstas a través exclusivamente de fórmulas burocráticas, y en las que el cumplimiento de la legalidad y una visión reactiva del ejercicio de la función directiva se convierte en el único parámetro a considerar - y que convirtió, en otro momento, a los funcionarios de Administración local con habilitación de carácter nacional en los protagonistas principales y guardianes celosos de ese proceso ${ }^{43}$ — en unas organizaciones con las capacidades ejecutivas y administrativas y con una visión proactiva necesaria para enfrentar esos procesos es, no me cabe duda, el gran reto a asumir ${ }^{44}$.

\footnotetext{
${ }^{43}$ Véase respecto de esta reflexión las contenidas en el trabajo de R. JIMÉNEZ AsENSIO, «Reflexiones sobre el marco ("el corsé") jurídico de la gerencia local», en el libro colectivo Gobierno local y modelo gerencial, Estudis 4, Fundació Carles PI i Sunyer, Barcelona 1999, págs.97 y ss.

${ }^{44}$ En cualquier caso, muy orientativo de la función desempeñada en esos momentos del régimen preconstitucional por los funcionarios con habilitación de carácter nacional y del esquema de toma de decisiones en las entidades locales en ese momento es la publicación del Gabinete de Estudios de la Secretaria General del Excmo. Ayuntamiento de Sevilla, 1976, titulada El Secretario de Administración Local.
} 
Aunque todo ello, quiérase o no, se ha de realizar sin menospreciar ni minusvalorar las funciones de control que son, por su propia naturaleza e importancia, imprescindibles para el adecuado ejercicio de la función de gobierno. Ni siquiera a costa de éstas. Una cosa será que el ejercicio de la acción de gobierno en nuestras entidades locales no pivote de forma exclusiva en los funcionarios con habilitación de carácter nacional como sucedió otrora y otra, muy distinta, volatilizar el ejercicio de funciones imprescindibles para un buen gobierno.

En cualquier caso, y si se acepta la necesidad de redefinir el liderazgo político y la función directiva en nuestros Gobiernos locales, es preciso poner de relieve que, como Soto Valle ha puesto de manifiesto, hay un presupuesto legal del que aún hoy parte nuestro sistema normativo local, e inclusive nuestro sistema de función pública, y que consiste en la opción, al menos hasta el momento, de que las funciones directivas corresponden, en primera instancia al menos, a los responsables políticos locales ${ }^{45}$. Pues no a otros actores, si se observa el sistema de atribución competencial a los distintos órganos de gobierno local, son a los que se les ha atribuido en el régimen local postconstitucional la dirección pública en sus dos facetas: como ejercicio de la acción de gobierno, pero también como dirección de la organización pública para alcanzar sus objetivos.

El personal eventual, aún con funciones directivas no exentas de discusión como acontece en el ámbito local ${ }^{46}$, no resulta ser un mal remedo de la ausencia de una función directiva en los Gobiernos locales y su selección y criterios de actuación tienen que ver más, y en mayor medida, con una prolongación de las funciones políticas que con una función directiva profesionalizada en el estricto sentido del término.

De otro lado, es preciso tener en cuenta las diferencias que la gestión de las organizaciones privadas presenta respecto de las organizaciones públicas. Losada Marrodán, en un excelente trabajo, ha explicado que las especificidades de la gestión pública implican también, dado el contexto

\footnotetext{
45 J.I. Sото ValLe, «Modernización y ámbito directivo: cinco tesis sobre el futuro de los Secretarios de Administración Local», El Consultor de los Ayuntamientos y los Juzgados, nº 11, 1999, págs. 1817 y ss. En el mismo sentido, puede verse del mismo autor, «Los Secretarios de Administración Local entre la gestión y el Control», Revista de Estudios Locales, número extraordinario, julio, 2003, págs. 161 y ss., donde pone de manifiesto que las funciones directivas clásicas — planificación, organización, coordinación y control — corresponden en su mayoría en el sistema normativo español a la dimensión política de la organización.

${ }^{46}$ Puede verse, a este respecto, el trabajo de X. Boltaina Bosch, «Empleo Eventual y Función Directiva en las Administraciones Locales», Revista de Estudios Locales, número extraordinario, Julio, 2003, págs. 9 y ss.
} 
en el que se desarrollan, importantes implicaciones para el trabajo directivo en el sector público fuertemente influenciado por el tipo de organización en que se desarrolla, los bienes que gestiona, el específico proceso de toma de decisiones y, finalmente, cómo se gestiona lo que se traduce en específicas competencias requeridas en los directivos públicos que difieren, en cierta medida, de las exigidas en la empresa privada y que, lógicamente, requieren una especialización ${ }^{47}$.

Respecto a estos elementos referidos, la dirección pública ofrecía en el ámbito local, al menos hasta la reforma de 2003 que ha variado sustancialmente algunas de dichas conclusiones, peculiaridades propias que ya habían sido puestas de manifiesto por la doctrina que se ha ocupado del tema -inclusive a algunas de ellas ya nos hemos referido páginas más atrás- y que podemos resumir en las siguientes ${ }^{48}$ :

- La colonización o usurpación del espacio directivo por los responsables electos en lo que se ha denominado «concejal asistencial»y «concejal ejecutivo», interfiriendo en el espacio de gestión y que implican dos tipos de anormalidad en la gestión local: de una parte, el olvido y la renuncia al espacio político de los electos precisamente para gestionar este espacio; de otra, la lesión de un principio constitucional como es el diseño de una Administración pública profesional y la frustración de los funcionarios pertenecientes a la función pública local que no encuentran espacio suficiente de ejercicio de su función.

- El marco institucional y organizativo existente en el régimen local no propicia singularmente la articulación de un espacio directivo al concentrarse en el Alcalde-Presidente las funciones ejecutivas y que éstas sólo pueden ser delegadas en responsables electos.

- La diversidad de regímenes utilizados para articular la función directiva propicia una cierta confusión que no facilita la profesionalización de este espacio. En efecto, junto a los responsables electos, es preciso aludir aquí al personal eventual que gracias a un «exceso» en el Texto Refundido de Régimen Local respecto de la

\footnotetext{
${ }^{47}$ C. Losada Marrodán, «Las especificidades de la gestión pública: implicaciones en la función directiva», Documentación Administrativa, no 241-242, 1995, págs. 407 y ss.

${ }^{48}$ R. JIMÉNEZ AsENSIO, «La Dirección pública en la Administración local: los funcionarios con Habilitación Nacional como directivos públicos», CUNAL, número extraordinario, 1997 y la obra ya citada sobre «Reflexiones sobre el Marco Jurídico....», op. cit. Asimismo, LONGO, F., «Política y Gerencia pública en los Gobiernos locales», en el libro colectivo Gobierno local y modelo gerencial, Estudis 4, Fundació Carles PI i Sunyer, Barcelona 1999
} 


\title{
dicción de la Ley de Medidas para la Reforma de la Función Públi- ca de 1984 y la Ley Reguladora de las Bases de Régimen Local de 1985 desempeñan aquí funciones directivas ${ }^{49}$, los contratos de alta dirección, los propios funcionarios de carrera, el personal laboral común y, sobre todo en municipios medianos y pequeños, los fun- cionarios con habilitación de carácter nacional.
}

\begin{abstract}
${ }^{49}$ En efecto, el artículo 176.3 del Texto Refundido de Régimen Local dispone que «Podrán ser desempeñados por personal eventual determinados puestos de trabajo de carácter directivo, incluidos en la relación de puestos de trabajo de la Corporación, de acuerdo con lo que dispongan las normas que dicte el Estado para su confección. En estos supuestos el personal eventual deberá reunir las condiciones específicas que se exijan a los funcionarios que puedan desempeñar dichos puestos.»

No obstante, y sin embargo, es preciso resaltar la valoración negativa, y sobre todo la interpretación restrictiva, que desde el punto de vista jurídico ha podido recibir el artículo 176 del Texto Refundido de Régimen Local. Así por ejemplo, doctrinalmente, A. Serrano Pascual: El Personal de las Entidades Locales. Análisis de su régimen jurídico. Ed. El Consultor de los Ayuntamientos y de los Juzgados, Madrid, 1997, páginas 200-201.

De otro lado, jurisprudencialmente se ha mantenido una visión restrictiva de los puestos de trabajo a ocupar por personal eventual basada en el concepto de «permanencia» de la función y negando la posibilidad de su provisión cuando las funciones atribuidas a dichos puestos no implican ésta. Así la Sentencia del Tribunal Superior de Justicia de Castilla y León de 8 de marzo de 1999 establecía que:
\end{abstract}

«TERCERO.-... El Tribunal Supremo ha venido a confirmar esta cuestión, en su Sentencia de 12 de diciembre de 1997 (RJ 199719587) que desestima el recurso del Ayuntamiento de Burgos contra la Sentencia del recurso 1370/1994, pero lo hace en forma tan categórica, que va mucho más lejos en el planteamiento de la Sentencia impugnada, dejando claro no sólo la aplicabilidad del artículo 15.1 de la Ley 30/1984, sino la interpretación que debe hacerse del mismo de cara a la posibilidad de creación de puestos de naturaleza laboral eventual, que por interpretación «a contrario sensu» del art. 15.1 f) párrafo segundo de la Ley 30/1984 sólo pueden ser creados, para tareas a desempeñar con carácter no permanente. Así dice la Sentencia aludida: - Por tanto, no es posible establecer como doctrina legal, como pide en este recurso el Ayuntamiento de Burgos, que no es necesaria la inclusión en la plantilla, relación de puestos de trabajo y oferta de empleo público de los puestos de trabajo que tengan carácter temporal. Es necesario que se cumplan otros requisitos y entre ellos, esencialmente, que se trate de realizar tareas de carácter no permanente, lo que significa que la Administración no puede contratar personal laboral de carácter temporal para realizar trabajos que tienen naturaleza permanente dentro de la organización administrativa, no trasladándose la temporalidad del contrato a la temporalidad del trabajo para el que tal contrato se verifica. Es decir, no se ajusta a la norma transcrita que se pretenda contratar con carácter temporal a una persona, en régimen de contrato laboral, cuando las tareas para las que se le contrata son de carácter permanente, sin que pueda evitarse la aplicación de la norma manteniendo que el contrato de trabajo es de duración determinada, esto es, de carácter temporal. El contrato debe ser temporal, pero además de ello las tareas que la persona contratada ha de desempeñar deben tener carácter no permanente dentro de la organización administrativa. Si tienen carácter permanente no pueden ser asignadas a personal contratado al amparo del párrafo segundo del artículo $15.1 \mathrm{f}$ ) de la Ley 30/1984-.»

De esta forma, y con la doctrina citada, la jurisprudencia ha rechazado la posibilidad de utilizar este sistema para un Encargado de Obras, aún cuando sus funciones a juicio de la entidad local se caractericen por ser de confianza y asesoramiento especial (Sentencia de 2 de marzo de 1999 del 
- La propia diversidad del régimen local que obliga, también en este espacio directivo, a plantear soluciones de «geometría variable» ya que difícilmente son trasladables sin más las reflexiones que se realicen para municipios de una cierta entidad poblacional y financiera con las que puedan realizarse cuando nos referimos pequeños municipios.

Con estas mimbres no puede extrañarnos en modo alguno que exista una cierta coincidencia entre los estudiosos del empleo público ${ }^{50}$, de que la definición de un modelo de dirección profesional en nuestro sistema de empleo público es una asignatura pendiente en la que existen limitaciones normativas e, inclusive, como ha indicado JIMÉNEZ AsENSIO, institucionales y culturales. Compleja, pero pendiente y que se debate entre la usurpación de funciones públicas por parte de la clase política a la que se hizo referencia en párrafos anteriores y la tendencia también existente de funcionarización del sistema directivo producto, lógicamente, del espacio no delimitado suficientemente entre la política y la burocracia pública. Ni el sistema de provisión de puestos mediante libre designación ni la existencia del denominado personal eventual dan cumplida respuesta a dicha necesidad. Tampoco el modelo de la LOFAGE trasladado con la Ley 57/2003, de 16 de diciembre, al espacio local, y que consagra un modelo mixto que opta fundamentalmente por la funcionarización, y de forma excepcional por la atribución de dichas funciones a quienes no reúnen las condición de funcionario público, parece la solución sobre todo si no se definen otras cuestiones previas, a saber: la definición del estatuto en que se integra dicho personal, su articulación con el resto de la función pública, la opción o no por unas condiciones socio-laborales regidas por el principio de universalidad con el sistema de empleo público, las condiciones de acceso a dicha categoría, el régimen de situaciones administrativas, de

Tribunal Superior de Justicia de Extremadura), de conductor de vehículos del Conseller (Sentencia de 5 de noviembre de 1998 del Tribunal Superior de Justicia de Valencia), Director Técnico de la Oficina de Urbanismo (Sentencia de 3 de marzo de 2000 y de 12 de abril del Tribunal Superior de Castilla y León) y, con un criterio contrario, la ha admitido en el caso de Secretaria particular del Alcalde (Sentencia de 28 de febrero de 1990 del Tribunal Superior de Justicia de Baleares) o de Ayudante del Gabinete de Prensa (Sentencia de 18 de septiembre de 1995 del Tribunal Superior de Justicia de Castilla y León).

Pero, ciertamente, si nos atenemos al ordenamiento local, éste permite que, no sólo funciones de confianza y asesoramiento especial, sino también funciones directivas se desempeñen por personal eventual.

\footnotetext{
${ }^{50}$ Por todos, la obra de R. Jiménez Asensio, Altos cargos y Directivos Públicos, IVAP, Oñati, 1998. Asimismo, y aunque se trata de un comentario sectorial a propósito de la potestad organizatoria contenida en la LOFAGE, puede verse el trabajo de A. PALOMAR OLMEDA, «Potestad organizatoria y directivos públicos», Actualidad Jurídica Aranzadi, año XII (2002), nº 531
} 
permanencia y de progreso, el sistema de formación exigible, etc... A lo más que se llega es, y asentado el sistema asimismo en la confianza política - ya que el nombramiento y cese es libre — es a establecer, como con acierto ha subrayado el autor anterior, a establecer un sistema «spoil system de circuito cerrado» 51

Pero, precisamente, y a propósito de esta última reflexión, aún otro elemento ha de añadirse a fin de disponer de una visión completa de este panorama complejo que resultan ser las funciones directivas en los Gobiernos locales ¿Es la dirección pública algo uniforme y extrapolable en las distintas Administraciones públicas y sectores de ésta? ${ }^{52}$.

La heterogeneidad del sector público y las diferentes funciones que éste cumple lleva a rechazar de forma natural la idea de generalizar conclusiones para todos los empleos y cargos públicos, y en lo que nos importa para los puestos directivos de la Administración local. Si, ciertamente, las distintas consideraciones que se realizan sobre la función directiva y la obtención de resultados tienen un grado de aplicabilidad alto en el sector público comercial o financiero que, en definitiva, oferta bienes y servicios al mercado junto al sector privado, o inclusive en la prestación de servicios públicos, dicho grado de aplicabilidad va proporcionalmente reduciéndose en la medida en que nos acercamos al grupo de empleos públicos que proveen bienes y servicios esenciales para la comunidad en forma exclusiva, o de forma transversal a la organización, en que las formas de organización y sistemas de gestión del empleo requieren consideraciones distintas ${ }^{53}$. Singularmente, en nuestro país, PRATs ha recordado que la administración burocrática es el sistema más racional para la gestión de las funciones exclusivas y superiores del Estado, las cuales implican normal-

\footnotetext{
${ }^{51}$ R. JimÉNez AsEnsio, «Política y Administración en la reforma del Gobierno local de 2003», en Anuario de Gobierno Local de 2003, Marcial Pons, 2004.

${ }^{52} \mathrm{Ha}$ de tenerse presente, a este respecto, que como ha puesto de relieve JimÉNEZ AsENSIO en la obra ya citada, amen de diferenciarse los directivos públicos de los altos cargos y de que existen en el Derecho español diversos regímenes jurídicos en el ejercicio de las funciones directivas, un Estatuto diferenciado de directivos públicos no puede olvidar el hecho cierto de que éste habría de ser un estatuto de mínimos que permitiese su adaptación a los distintos sectores funcionales y territoriales de nuestras Administraciones

${ }^{53}$ Los bienes que Bresser ha denominado «actividades exclusivas del Estado» (L. BRESSER, «Da Administracao Publica Burocrática à Gerencial», informe presentado al Seminario Reforma do Estado Na America Latina e no Caribe) o que DROR ha denominado «funciones estatales de orden superior» (Y. DroR, «Fortalecimiento de la capacidad de los Gobiernos en materia de formulación de Políticas), documento presentado a la XII Reunión de Expertos del Programa de Naciones Unidas en materia de Administración y Finanzas Públicas, celebrado en Nueva York del 31 de junio a 11 de agosto de 1995.
} 
mente régimen de monopolio y ejercicio de autoridad ${ }^{54}$. Y entre las que se encuentran incluidas, sin duda, las funciones desempeñadas por estos funcionarios con habilitación de carácter nacional.

Desde este punto de vista, y si ciertamente, como hemos intentado poner de manifiesto, asistimos a un momento en que las nuevas exigencias que se plantean a nuestros Gobiernos locales demandan una nueva concepción en que los procesos de toma de decisiones y la gestión de los servicios públicos no pueden descansar exclusivamente en la garantía del principio de legalidad como objetivo en si mismo a cumplir ya que el Derecho no es sino algo instrumental a la actividad política de consecución de fines, no es menos cierto que la garantía del efectivo cumplimiento y respeto de éste es un prius imprescindible de toda la actividad administrativa cuya efectiva garantía es también una condición de eficacia de la acción pública ${ }^{55}$, y cuyo ejercicio implica el disponer de unos funcionarios con unos conocimientos, competencias y habilidades que, hoy por hoy, parecen cumplir con holgura los funcionarios con habilitación de carácter nacional sobre todo si se llega a la conclusión de que determinadas funciones, olvidémonos por un momento de los cuerpos que actualmente las sirven, exigen para su correcto desempeño un estatuto específico que garantice la posibilidad e independencia en su ejercicio. Pero sobre esto volveremos más adelante.

Y esto implica, al menos en el régimen local español, partir de la base de que la función superior o directiva no parece que haya de ceñirse en exclusiva a la consecución de resultados producto de la prestación de servicios externos. Por supuesto que ésta es su manifestación más prototípica, pero los destinatarios de la acción pública — como también de la privada - pueden ser también internos y no parece haber duda de que los núcleos de funciones reservados en exclusiva a los funcionarios de Administración local con habilitación nacional forman parte de estas funciones superiores y son de carácter imprescindible para una buena gestión del gobierno local. Bien es verdad que su función tendrá que ver con aquellos procesos de decisión atinentes a garantizar el Estado de Derecho, la segu-

\footnotetext{
54 J. Prats, «Reinventar la Burocracia y construir la nueva Gerencia Pública», documento que aborda para América Latina específicamente pero que por la validez de sus reflexiones puede ser perfectamente extrapolado la necesidad de distinguir funciones estatales para las cuales la utilización del management es más acertada o no. Puede consultarse en su versión integra en http://www.iigov.org/iigov/pnud/bibliote/documentos/docu0063.htm

55 Puede verse respecto a la errónea contraposición entre Derecho y Management el excelente trabajo de J. Prats, «Derecho y Management en las Administraciones Públicas», Economiaz, n 26 , pág. 130 y ss.
} 
ridad jurídica y el principio de legalidad, pero ello no es óbice para reconocer, asimismo, la incardinación de éstas en las funciones superiores de dirección, en este caso en su vertiente de control en sentido positivo, de las entidades locales. Porque, en caso contrario, qué otra consideración pueden tener las funciones desarrolladas por tales funcionarios.

\section{LAS MEDIDAS CONTEMPLADAS EN EL PROYECTO DE LEY DE MODERNIZACION DEL GOBIERNO LOCAL}

En junio de 2003 el Boletín Oficial de las Cortes Generales publicaba el Proyecto de Ley de Modernización del Gobierno Local y finalmente en el $B O E$ de 17 de diciembre del mismo año se publicaba la Ley 57/2003, de 16 de diciembre, de Medidas para la Modernización del Gobierno Local. Denominación curiosa, inclusive desconcertante, que apegada a los movimientos de reforma administrativa que hicieron furor en la década de los noventa, y cuya sola mención parecía provocar efectos benéficos y beneficiosos sobre la materia que era objeto de aplicación de la misma, se adopta en esta Ley para dar cabida a un conjunto heterogéneo de medidas.

En efecto, lo cierto es que bajo esa equívoca denominación, que en realidad engloba elementos distintos o más amplios a los acogidos en dicha Ley, se pasa a regular un conjunto de materias diversas que, en algunos casos, poco o nada tienen que ver con la misma sin que ello sea óbice para reconocer la importancia de las mismas.

De esta forma, dicha Ley, que tuvo su origen en la que se quería que fuese una Ley de Grandes Ciudades producto tanto de las reivindicaciones de éstas como del Informe que el Ministerio de Administraciones Públicas remitió en octubre del año 2001 al Senado y de la proposición no de Ley aprobada en marzo de 2003 por una amplia mayoría parlamentaria, se ha pasado a un Proyecto legislativo que engloba un conjunto variopinto de medidas que afectan a la organización de municipios estableciendo un régimen común y otro específico para los municipios de población superior a 250.000 habitantes y capitales de provincia de población superior a 175.000 habitantes (y municipios capitales de provincia, capitales autonómicas o sedes de instituciones autonómicas y municipios con más de 75.000 habitantes siempre que así se decida por las Asambleas Legislativas), a las competencias de las Diputaciones Provinciales, a la prestación de servicios públicos, al régimen de la función pública local, a la potestad sancionadora local, a las ordenanzas fiscales y a las reclamaciones econó- 
mico-administrativas, a los mecanismos de cooperación interadministrativos, a las medidas para fomentar la participación ciudadana en la toma de decisiones, etc...

¿Era preciso abordar dichos aspectos? No me cabe duda de que muchas de las materias objeto de reforma legal tienen una indudable importancia y que, inclusive, se ha hecho un adecuado tratamiento de las mismas. En otras mantengo dudas importantes tanto en cuanto a la idoneidad de las mismas como respecto de la técnica legislativa empleada para regularlas que es notoriamente mejorable.

Sin embargo, y a la vista de las reflexiones que en su momento realizamos sobre los retos del gobierno local en la actualidad, la clave para juzgar la pretendida modernización de nuestras entidades locales será preguntarnos si se responde acertadamente a éstos en las medidas organizativas que se contemplan. Recordemos, en forma sintética, que sin perjuicio de actualizar en determinados aspectos la legislación local como acertadamente hace el proyecto en cuanto a las formas de gestión de los servicios públicos o el intento de superación de los problemas que aquejaban al ejercicio de la potestad sancionadora local, lo cierto es que los problemas que dificultaban aspectos organizativos en las entidades locales se centraban en la articulación equilibrada de la dirección política, la función directiva y el engarce de ambas con una función pública profesional que, además, diese respuesta a tres realidades presentes en el régimen local español: por un lado, una nueva realidad local, pasada una época en que las prioridades se centraron en la prestación de unos servicios básicos a la ciudadanía, que demandan una nueva orientación de las mismas como gobierno del territorio y no simplemente como entidades prestadoras de servicios y, por ello, un nuevo estilo de hacer política local y un nuevo liderazgo; en segundo lugar, la diversidad de nuestro régimen local donde conviven entidades locales de muy diferente nivel de complejidad organizativa y donde no es posible hacer una lectura uniforme de lo que significa la legítima representatividad de las comunidades locales y las dimensiones adecuadas para la prestación de servicios públicos necesarios y la asunción de los anteriores retos; y, por último y ciñéndonos a los aspectos claves en la materia que nos ocupa, una organización de la función pública local, incluida la función directiva, caduca — que todavía hunde sus raíces en el RD 3046/1977, de 6 de octubre - y que, en cuanto a la función directiva, ponía de manifiesto un déficit importante en cuanto a su regulación, institucionalización y profesionalización.

Adelantemos ya, sin perjuicio de que se razonará dicha afirmación, que al menos en cuanto al tema organizativo y su conexión con la función 
pública local el juicio que merece esta Ley ha de ser necesariamente negativo. Falta de coherencia de las medidas con lo qué significa el Gobierno local y las peticiones de las grandes ciudades, con casi toda seguridad un incremento injustificado del gasto público corriente en numerosas entidades locales, desarticulación de la reserva de funciones a los funcionarios con habilitación de carácter nacional sin establecer otras alternativas lo que sin duda constituye uno de los objetivos principales de la Ley, falta de estructuración de una función pública directiva profesional, etc... son muchas de las materias que en el debe de esta Ley se encuentran presentes.

\section{El ámbito de aplicación de las medidas a adoptar, la definición de lo básico en dicha norma y el ejercicio de la acción de gobierno en el ámbito local}

Lo primero que hay que subrayar es que las medidas organizativas contempladas en dicho proyecto han ido progresivamente, tras los diversos borradores, anteproyectos y la pertinente tramitación parlamentaria, incrementando su ámbito de aplicación. Lo cierto es que el trámite parlamentario ha derivado, sin una adecuada explicación, en la eventual extensión de las mismas hasta municipios de población superior a 75.000 habitantes cuando así se decida por las CCAA.

Y es que, en efecto, resalta de dichas medidas lo referente a su ámbito de aplicación: ¿existe algún motivo para que la organización especial establecida sea aplicable a los municipios de más de 250.000 habitantes o 175.000 habitantes cuando se es sede de una institución autonómica o se es capital de provincia? ¿Qué justifica su eventual extensión a municipios de población superior a 75.000 habitantes? ¿Por qué dejar fuera de la posibilidad de dicha organización a municipios de inferior población de derecho pero que, por diversas circunstancias — ser un enclave turístico por ejemplo-, presentan idénticas características a los incluidos en la misma?

Es más, ¿cuál es la razón para que dicha medida no sea aplicable a las Diputaciones Provinciales? Curiosamente, y de forma hasta cierto punto incomprensible, dichas medidas en lo que suponen, como ahora tendremos oportunidad de comprobar, de reestructurar la dirección política y la función directiva en las entidades locales no son aplicables a las Diputaciones Provinciales (sí a los Cabildos) a pesar de que la complejidad organizativa de éstas, las funciones que desarrollan y el resto de elementos que puede imaginarse han estado presentes en dicha decisión concurren en plenitud en éstas (?). O no se juzga relevante que el Pleno provincial se 
configure como un verdadero órgano de debate de las grandes políticas provinciales sobre todo si a la par se han potenciado las competencias de las Diputaciones Provinciales asignándoles el fomento del desarrollo económico y social y la planificación en el territorio provincial. ¿Por qué no se considera necesario, en este caso, disponer de una Junta de Gobierno local fuerte o que en el Gobierno provincial se integren personas que no ostentan la condición de electos reforzando el perfil ejecutivo de la Junta de Gobierno?

La Ley parte, para este tipo de municipios, de una doble lectura en la que seguramente una gran parte de los que nos dedicamos al estudio del régimen local podemos compartir: la necesidad de fortalecer el perfil ejecutivo de éstos municipios y la de separar las función de debate y de control radicadas con preferencia en el Pleno de las funciones ejecutivas que se pretenden radicar en la denominada Junta de Gobierno, configurando adicionalmente al Alcalde, según se confiesa en la Exposición de Motivos, en el principal órgano de dirección de la política, el gobierno y la administración municipal que ostenta la representatividad y aquellas funciones ejecutivas necesarias para el ejercicio de su función y que preside aquella.

Incluso admitiendo que dicho objetivo se consigue cabe preguntarse si se hace acertadamente, ¿hay un exceso de regulación en lo que debería ser una legislación de bases? ¿Hubiese sido más adecuado eliminar aquellos obstáculos que, diagnosticados desde hace tiempo, impedían conseguir tales objetivos y remitir a la legislación autonómica y a la potestad autoorganizatoria la lectura tanto de qué municipios exigen dichas soluciones, cómo de qué solución es la adecuada en el municipio concreto de que se trate? ¿Se da respuesta a la articulación de una función pública profesionalizada? ¿Qué coste, en términos de gasto corriente, tendrán las medidas adoptadas? Preguntas todas ellas que son las que realmente nos pueden orientar en el debate.

Refirámonos, por ello, al primer punto. El exceso en la definición de lo básico en el régimen organizativo local. Y comencemos por decir que, desde nuestro punto de vista, el detallismo contenido en una legislación de bases, como resulta ser la Ley de Modernización, resulta esperpéntico y difícilmente compatible con la dimensión organizativa de la autonomía local ${ }^{56}$.

\footnotetext{
${ }^{56}$ De acuerdo con la STC 42/1983, «lo que la Constitución persigue al conferir a los órganos centrales del Estado la competencia exclusiva para establecer las bases de la ordenación de una materia determinada (...) es que tales bases contengan una regulación normativa uniforme y de vigencia en toda la Nación, con lo que se asegura,en aras de intereses generales superiores a los de cada
} 
Éste es, digámoslo de una vez por todas, necesariamente un punto necesitado de reflexión. La Carta Europea de Autonomía Local, en su artículo 6.1, precisa que sin perjuicio de las disposiciones más generales creadas por la Ley, las Corporaciones locales deben poder definir por sí mismas las estructuras administrativas internas con las que pretenden dotarse, con objeto de adaptarla a sus necesidades específicas y a fin de permitir una gestión eficaz. Límite al poder normativo del Estado o de las CCAA que no es sino una consecuencia de que las potestades de autoorganización constituyen la expresión más genuina, el núcleo mismo, de la autonomía local.

Ciertamente nuestro Tribunal Constitucional no contribuyó a fortalecer dicha consideración. Como sabemos la STC 214/1989, de 21 de diciembre, tuvo como consecuencia directa, al hacer prevalecer la legislación autonómica de desarrollo sobre la potestad autoorganizatoria local, una cierta indeterminación, y seguramente una reducción, del espacio atribuido a ésta a favor de abrir un ámbito de decisión a la normativa autonómi$\mathrm{ca}^{57}$. Sin embargo, y aunque dicha perspectiva pueda ser discutible, y partiendo de la progresiva interiorización del régimen local en el ámbito autonómico, no es menos cierto que, a la vista de las soluciones organizativas impuestas por la Ley de Modernización a modo de reglamento organizativo (existencia preceptiva de asesoría jurídica, organización de las unidades de fiscalización y control, organización de las áreas de acción administrativa, fórmulas para la participación ciudadana, etc...), ni existe espacio para el legislador autonómico que verá su papel reducido a ser un legislador reglamentario o a optar por extender o no las medidas establecidas en dicha Ley, y desde luego el espacio normativo local queda difuminado precisamente en este tipo de municipios en que su complejidad aconsejaría más que cerrar las posibilidades organizativas abrir un amplio abanico de éstas.

Puede alguien explicar, a título de ejemplo, porque los municipios sujetos al régimen especial establecido en dicha Ley han de tener o no una ase-

Comunidad Autónoma, un común denominador normativo» del bloque de constitucionalidad (STC 48/1988), añadiendo que «el sentido de ese común denominador normativo se halla en buena medida no tanto en la uniformidad cuanto en la posibilidad que el mismo abre de que, a partir del mismo, cada Comunidad Autónoma, en defensa de su propio interés general, podrá establecer las peculiaridades que le convengan en ejercicio de las competencias que haya recibido como propias» (ATC 288/1996) y sin que quepa realizar con ello un vaciamiento competencial autonómico (SSTC 69/1988 y 80/1988).

${ }^{57}$ Véase el trabajo de L. PAREJO Alfonso, «La potestad de autoorganización de la Administración Local», DA, $\mathrm{n}^{\circ} 228,1991$. Con posterioridad, y del mismo autor, La potestad normativa local, Marcial Pons, Madrid, 1998. 
soría jurídica y que la decisión sobre dicha cuestión sea marcada por una Ley de Bases. No dudo que sea razonable, pero tampoco dudo que es una decisión, como otras también recogidas en la Ley motivadas en mayor medida por la limitación de funciones a una clase de funcionarios, y que creo que está naturalmente inserta en la potestad de autoorganización de sus servicios de las entidades locales, que repitámoslo forma parte del núcleo de su autonomía, y que no integra para nada, antes bien al contrario, el conjunto de materias sobre las que el legislador, ya sea estatal o autonómico, deba pronunciarse. Es desde luego, más que una Ley de Modernización en este punto, una Ley regresiva, uniformista, que desconfía de la autonomía local y que, mucho me temo, supone un paso atrás en la construcción de la arquitectura del régimen local en España. Han podido aquí más otras razones, a las que ya hicimos referencia, que la renovación de esta arquitectura transcurridos casi veinte años de la reforma del régimen local.

Precisamente por las razones anteriores un segundo aspecto que al interprete de dicha norma mueve a reflexión es la confusión que introduce entre la dirección política, las funciones directivas (que como elemento positivo por vez primera se reconocen existen en el Gobierno local) y las estrictamente administrativas o funcionariales. Diversos aspectos del texto de la Ley finalmente resultante nos llevan a esta conclusión.

Desde hace algún tiempo, y como consecuencia de la necesidad de fortalecer la vertiente ejecutiva del Gobierno local, y garantizar un funcionamiento más eficiente de los equipos de gobierno a constituir para la dirección de los Ayuntamientos de gran complejidad organizativa, se había propugnado por un conjunto de autores la posibilidad de delegación de ciertas facultades y atribuciones realizadas a los órganos unipersonales ejecutivos del Gobierno local a electos, pero también, y aquí radicaba la propuesta, a no electos ${ }^{58}$. La posibilidad apuntada, que resultaba vetada tanto por la legislación de función pública como por la legislación de régimen local, perseguía que la constitución del equipo de gobierno en el ámbito local obedeciese a parámetros similares a los que acontecían en los gobiernos autonómicos, profundizando en la configuración del Pleno como órgano deliberante, normativo y de control — separando, por tanto, las funciones de Alcalde y Presidente del Pleno- y ampliando el margen de discrecionalidad del Alcalde en la constitución del equipo de gobierno favoreciendo la profesionalización de la gestión y evitando la duplicidad

\footnotetext{
${ }^{58}$ En este sentido, y comentando la reforma acontecida en 1999, puede consultarse mi trabajo «La configuración de los órganos unipersonales en la reforma del Régimen Local», REALA n 280-281, 1999, págs. 323 y ss.
} 
de funciones que la realidad organizativa local mostraba se producía entre los Concejales con delegación en un área de gobierno y los Directores de los distintos servicios ya fuesen funcionarios, personal eventual u otra de las fórmulas utilizadas habitualmente. La solución, que lógicamente habría de ser asimétrica respecto del conjunto de municipios que componen el mapa municipal español, perseguía con ello clarificar el esquema de funcionamiento entre los órganos ejecutivos y deliberantes (en la línea ya apuntada por la Carta Municipal de Barcelona) y favorecer la diversidad y diferenciación en el Gobierno local, básicamente a través de su potestad de autoorganización, sin la intervención del legislador estatal o autonómico que sólo diseñarían los elementos esenciales del sistema de gobierno.

De nuevo aquí la Ley resulta confusa y adopta soluciones a «metta strada» entre las soluciones organizativas existentes hasta el momento, y que seguirán rigiendo para el resto de los municipios no incluidos en su ámbito de aplicación y las Diputaciones Provinciales, y las propuestas efectuadas que pueden no redundar en conseguir los objetivos antes apuntados. Son soluciones que ni se insertan en el modelo mayoritario en Europa, y hasta ahora en España, de que el órgano ejecutivo colegiado esté integrado por concejales, ni tampoco en las soluciones mixtas de Finlandia y Suecia donde no necesariamente tienen que ser concejales, pero tampoco en las soluciones de los Países Bajos, Italia o Portugal donde la pertenencia al ejecutivo y el cargo de concejal resulta incompatible ${ }^{59}$. No la opción elegida es una solución singular, como decimos a «metta strada», entre las distintas opciones que mucho me temo no dará ningún resultado.

La Ley en su artículo 130, y adoptando el modelo de la LOFAGE, parte de la distinción entre órganos superiores y órganos directivos. Como es bien conocido en dicho texto legal que ordena la organización estatal existe una distinción entre los órganos superiores, constituidos por los Ministros y Secretarios de Estado y que pueden o no ser electos como Diputados o Senadores, y los órganos directivos que quedan integrados por los Subsecretarios, Directores generales y Subdirectores generales que dependen de los anteriores. En nuestro caso, el susodicho artículo 130, partiendo de dicha distinción, distingue también entre órganos superiores, en este caso Alcalde y miembros de la Junta de Gobierno, y órganos directivos en los que encuadra a Coordinadores generales, dependientes de éstos a Directores generales u órganos similares que culminen la organización

\footnotetext{
${ }^{59}$ Véase el interesante estudio que sobre la configuración de los ejecutivos en Europa han publicado J. Magre Ferrán, y X. Berthana Horta, «El Alcalde como líder político y ejecutivo en los países de la Unión Europea», Revista de Estudios Locales, número extraordinario, julio, 2003, págs. 69 y siguientes.
} 
administrativa dentro de cada una de las grandes áreas o concejalías. Es decir, la Ley parece seguir optando por un modelo departamental al frente del cual, y como novedad, parece que podrá estar un concejal o un miembro no electo de la Junta de Gobierno. De forma complementaria, y ciertamente a nuestro juicio en la buena dirección, el texto ha suprimido la imposibilidad de delegación en órganos no electos de las atribuciones del Alcalde y Junta de Gobierno.

No me cabe duda de que el régimen local presenta diferencias significativas que deben ser objeto de reflexión para su configuración, y precisamente, por ello, no cabe, desde mi punto de vista, mimetizar soluciones y forzar su adaptación a otros modelos cuando soluciones más simples podrían evitar una administración burocratizada y de excesivos niveles jerárquicos.

Y es que, efectivamente, qué sentido tiene que no sean los miembros de esa Junta de Gobierno que se pretende configurar como el órgano de dirección política de la actividad del ente local y al que se le asignan funciones ejecutivas y administrativas muy relevantes, ya sean electos o no y sin límite alguno, los que figuren, en este caso sí a similitud de las Comunidades Autónomas o del Estado, al frente de las distintas áreas de gobierno sin esa artificiosa distinción entre órganos superiores y directivos, adoptada desde la organización de la Administración del Estado, pero que podría no tener mucho sentido en el sistema de Gobierno local. La realidad, sin embargo, parece ser otra. El artículo 123.1.c) declara expresamente que los Coordinadores generales a quienes se atribuye las funciones de coordinación y dirección de las distintas áreas de gobierno dependerán directamente de los miembros de la Junta de Gobierno Local, pero no forman parte de ésta, aunque sí pueden asistir a sus sesiones a convocatoria del Alcalde. Se configura así, de nuevo, un régimen mixto en el que finalmente no se entiende nada bien la figura de los Coordinadores generales o, alternativamente, la inclusión de esos no electos respecto de los cuales ni su Estatuto queda regulado claramente salvo en lo que se refiere a sus derechos económicos y prestaciones sociales que serán idénticas a los miembros electivos, ni su límite en un tercio de los miembros de esa Junta de Gobierno, ni su articulación con la función directiva que el propio texto normativo intenta instaurar.

La solución adoptada, en mi opinión, salvo aumentar los cargos de designación política en los municipios incluidos en su ámbito de aplicación pocas o ninguna función cumple, pues su virtualidad hubiese dependido de dar una respuesta adecuada a las cuestiones planteadas en el párrafo anterior y, de esta forma, quiérase o no, y por la propia dinámica de 
nuestro sistema político que la experiencia pone de manifiesto, su integración responderá en numerosas ocasiones a un personal de confianza política que no resultó incluido en las listas electorales o que simplemente no resultó electo en otro ámbito.

¿No hubiera sido más claro, y al mismo tiempo más razonable, que esos Coordinadores Generales hubiesen sido los que se hubiesen integrado en la Junta de Gobierno como no electos? ¿No hubiese sido, además, más económico? ¿No incrementa la regulación establecida en la Ley innecesariamente el número de niveles jerárquicos, con el subsiguiente incremento de la inflación organizativa que ya se vive en nuestros Gobiernos locales, desde el órgano que adopta la decisión hasta la efectiva ejecución de las misma?

\section{La función directiva}

La función directiva se articula, ya lo hemos mencionado, en torno a los denominados Coordinadores Generales — que, como ya hemos advertido, no forman parte de la Junta de Gobierno- y de los Directores Generales que en principio dependen de aquél. Aunque, ciertamente, también parece que podrán existir niveles complementarios de éstos establecidos en este caso por el Alcalde (artículo 123.1.c) que, sin embargo, no tienen carácter de órganos directivos (artículo 130.1). Se atribuye también tal condición de órganos directivos a los siguientes órganos: Secretario General del Pleno, Interventor General Municipal, titular de la Asesoría Jurídica, titular del órgano de apoyo a la Junta de Gobierno Local y al concejal-secretario de la misma y al titular del órgano de gestión tributaria en caso de que se decida su creación.

El modelo adoptado descansa, amen de la influencia de la LOFAGE, en dos notas: por un lado, que para desempeñar dichos órganos directivos se tenga de forma previa la condición de funcionario de carrera del Estado, las Comunidades Autónomas o las Entidades Locales o funcionarios con habilitación de carácter nacional pertenecientes al Grupo A ${ }^{60}$, es decir,

\footnotetext{
${ }^{60}$ Carece desde nuestro punto de vista de sentido, por innecesaria, la especificación realizada a favor de los funcionarios con habilitación de carácter nacional y establecida en el artículo 130.3. Hasta ahora, al menos que yo sepa, éstos, sin perjuicio de su necesaria habilitación para el ejercicio de las funciones reservadas a los mismos, eran funcionarios de Administración local. ¿Por qué referirse en concreto a una Escala de funcionarios de la Administración local? No existe, además de los funcionarios del Estado, de las CCAA y de las Entidades Locales otro tipo de funcionarios, en caso contrario habría que haberse referido también específicamente a los Cuerpos Docentes Universitarios, a la Administración militar, etc... ¿No hubiese sido técnicamente más correcto, si
} 
que la titulación exigida para el ingreso en el Cuerpo o Escala sea la de Doctor, Arquitecto, Licenciado, Ingeniero, Arquitecto o equivalente; en segundo lugar, dicho nombramiento se sostiene sobre la confianza política ya que ningún otro requisito se exige para el nombramiento, sin ni siquiera hacer referencia a la condición establecida en el artículo 6.10 de la LOFAGE referido a la exigencia de criterios de competencia profesional y experiencia para el nombramiento de dichos órganos directivos lo que notoriamente determina un tratamiento todavía más desfavorable que el establecido en el sector estatal. Pero ni tampoco sobre su permanencia ya que ésta se basa exclusivamente, sin ningún otro criterio basado en la evaluación de la gestión, en el mantenimiento de la confianza política ${ }^{61}$.

El sistema, como en el caso de la LOFAGE, también permite el desempeño de dichos cargos directivos a otras personas que no reúnan el carácter de funcionario de carrera, pero en este último caso habrá de ser el Pleno, al determinar los niveles esenciales de la organización municipal, el que permita que, en atención a las características específicas del puesto directivo, su titular no reúna la condición de funcionario de carrera. Y en estos supuestos si que se exige que su nombramiento se realice de forma motivada y de acuerdo con criterios de competencia profesional y experiencia en el desempeño de puestos de responsabilidad en la gestión pública o privada.

De esta forma, la regulación establecida arroja numerosos interrogantes. En primer término es preciso reflexionar sobre la creación de este espacio entre la política y la gestión, y es que aún siendo positivo la definición de un espacio directivo la más elemental lógica conduce a presumir que éste se define por características singulares y la exigencia de ciertos conocimientos, experiencia o habilidades que no reúne, en forma ordinaria, la función pública profesional ${ }^{62}$. En caso contrario no sería preciso. Y si esto es así parece que algo más que ostentar la condición de funcionario de carrera y poseer una titulación superior es exigible.

En segundo lugar, ¿qué justifica exigir, sin embargo, esas características cuando no se es funcionario de carrera? La utilización de un criterio

ésta era la opción elegida, haberse referido a la condición de funcionario de carrera de cualquiera de las Administraciones públicas?

${ }^{61}$ La LOFAGE prevé que los órganos directivos, en el desempeño de sus funciones, estarán sujetos a la responsabilidad profesional, personal y directa por la gestión desarrollada y sujetos al control y evaluación de la gestión por el órgano superior o directivo competente.

${ }^{62}$ Puede verse, a este respecto, el volumen Repensar el paper del gestor públic en el segle XXI, Escola d’ Administració Pública de Catalunya, Barcelona, 2003. 
distinto en el personal que no reúna la condición de funcionario pone, aún más de manifiesto si cabe, la artificiosa y desnaturalizada creación de este espacio directivo.

En tercer lugar, ¿cómo se justifica que un puesto directivo, si se ha partido de la regla general de que éste sea funcionario público, no ha de desempeñarse por alguien que no tenga dicha condición? ¿Qué diferencias existen entre los puestos de trabajo de carácter directivo a los que se exige la condición previa de ser funcionario público y los que no exigen dicha condición? La contradicción resulta, como puede verse, de identificar un espacio directivo por una condición previa como la de funcionario de carrera y no un conjunto de competencias, habilidades o requisitos que hayan de reunir los que hayan de desempeñar dichos puestos de trabajo, aislando unas funciones para las cuales se exigen requisitos distintos a los que, de un lado, la política y, de otro, la burocracia profesional exigen. No conjugando ambos criterios como realiza la Ley.

Pero, junto a estas cuestiones, que sin duda son capitales ya que la definición de un espacio directivo no puede realizarse sin la definición del espacio en sí, es decir, de los requisitos singulares de acceso y permanencia en dicho espacio, otras más no quedan debidamente dibujadas en el texto de la Ley. Por de pronto, ni el régimen retributivo de los mismos queda claro (sólo que corresponde al Pleno fijarlo), y, por ello, ni los conceptos que lo integrarán, como influyen éstos en el régimen funcionarial exigido y ni siquiera si éstos se vincularán decisivamente al desempeño, el régimen de sus prestaciones sociales, etc... Tan sólo se contempla que éstos quedarán en situación de servicios especiales (artículo 2 de la Ley) y que están sujetos al régimen de incompatibilidades establecido en la Ley 53/1984, de 26 de diciembre, de Incompatibilidades del personal al servicio de las Administraciones Públicas.

En definitiva, mucho nos tememos que esta regulación, más que una profesionalización del espacio directivo a pesar de exigir el requisito de ser funcionario de carrera, provocará, de nuevo, que dicho espacio directivo deficientemente configurado, ya que no se olvide que tampoco desaparece el personal eventual o al menos se limita el ejercicio de funciones directivas por éste (dada la regulación hubiese sido aconsejable la modificación del artículo 176 del Texto Refundido de Régimen Local), sea también colonizado por personas que más que a la competencia profesional, por muy funcionarios de Grupo A que sean, responde a la confianza política.

Fruto de esa indefinición y deficiente articulación resulta su correlativo impacto en las competencias para la organización de la función directiva. 
Corresponde al Pleno (artículo 123 c): la determinación de los niveles esenciales de la organización municipal entendiendo por tales las grandes áreas de gobierno; los Coordinadores generales directamente dependientes de los miembros de la Junta de Gobierno Local, con funciones de coordinación de las distintas Direcciones Generales u órganos similares integradas en la misma área de gobierno, y de la gestión de los servicios comunes de éstas u otras funciones análogas; y las Direcciones Generales u órganos que culminen la organización administrativa. Por su parte, el artículo $124 \mathrm{~K}$ ) atribuye al Alcalde la competencia para establecer la organización y la estructura de la Administración municipal ejecutiva competencia del Alcalde (en realidad el número de cada uno de tales órganos). Aunque la dicción del precepto no queda nada clara ya que si al frente de cada área de gobierno hay un Coordinador general y éstas son establecidas por el Pleno difícilmente el Alcalde puede establecer el número. Inclusive, y para aumentar la complejidad, se prevé la posibilidad de que por parte del Alcalde se establezcan niveles complementarios inferiores que no parecen pertenecer a la estructura administrativa ya que, estrictamente, la aprobación de la relación de puestos de trabajo resulta atribuida a la Junta de Gobierno Local (art. 127.1 h) y en éstas no parece que debieran integrarse los órganos directivos si seguimos el modelo de la LOFAGE (artículo 10), pero que, sin embargo, tampoco aparecen enunciados como órganos directivos.

\section{Los funcionarios con habilitación de carácter nacional}

Ciñéndonos a los funcionarios con habilitación de carácter nacional la Ley finalmente resultante, a diferencia del Proyecto de Ley originariamente presentado y paradójicamente dada una de las finalidades, un tanto inconfesables, con qué surgió, ha respetado un importante ámbito de acción para los mismos y ha disminuido el impacto de las medidas acordadas. Por de pronto ha abierto el espacio directivo ordinario a estos funcionarios, si bien también es cierto que, pese a ello y al menos en lo que se refiere a la Secretaria, provoca un serio desdibujamiento de la misma.

En principio dicha Ley, consagra la ruptura del paradigma de que la función de Secretaria, comprensiva de la fe pública y del asesoramiento legal preceptivo, corresponde a un funcionario público y, más en concreto, en la función pública local a los funcionarios con habilitación de carácter nacional. La ruptura, por cierto, se lleva a cabo sin modificar expresamente como hubiese sido aconsejable, además, el artículo 92.2 de la Ley 7/1985, de 2 de abril, Reguladora de las Bases de Régimen Local, que 
reserva la función de fe pública a personal sujeto al Estatuto funcionarial. Y, sin duda, esta primera medida mueve a reflexión ¿Es o no la función de fe pública y de certificación algo reservado al estatuto funcionarial? Lo que parece claro es que parece equívoco que una misma función pueda serlo o no en uno u otro órgano y en uno u otro municipio.

$\mathrm{Y}$ es que, en realidad, en esta nueva Ley desaparece como tal la figura del Secretario Municipal que se desdobla en dos figuras: la del Secretario General del Pleno que también lo será de las Comisiones de éste -y que en el Proyecto de Ley ni era General y ni siquiera era órgano directivo a diferencia del Interventor General ${ }^{63}$ _, y la del Concejal-Secretario de la Junta de Gobierno. En efecto, si bien la Secretaria General del Pleno con las funciones que a ella se le asignan (artículo 122.5), queda reservada a los funcionarios con habilitación de carácter nacional ${ }^{64}$, no ocurre lo mismo con la Secretaria de la Junta de Gobierno Local que corresponderá a un Concejal $(i$ ?) que redacta las actas de las sesiones y certifica sobre sus acuerdos, bien es cierto que se prevé la existencia de un órgano de apoyo de éste que habrá de ser un funcionario con habilitación de carácter nacional. Disposición establecida, no se sabe muy bien para qué ni por qué ${ }^{65}$, y que solo pone de manifiesto la incoherencia de esta Ley que se ha debatido entre haber mantenido la reserva de función muy desdibujada o

\footnotetext{
${ }^{63}$ Consecuencia de lo cual su nombramiento correspondía en el Proyecto de Ley a órganos distintos: el Secretario del Pleno a éste y la del Interventor General a la Junta de Gobierno. La redacción final de la Ley unifica el nombramiento de todos los cargos directivos en la Junta de Gobierno, y establece adicionalmente una suerte de estatuto singular para el Secretario que, aún siendo órgano directivo, su función y estatuto podrá ser objeto de regulación por las normas orgánicas que regulen el Pleno y sus retribuciones son asimismo, a diferencia del resto de funcionarios con o sin habilitación de carácter nacional, fijadas por el Pleno.

${ }^{64}$ Las funciones que comprende dicha Secretaria son las siguientes: redacción y custodia de las actas, así como la supervisión y autorización de las mismas, con el visto bueno del Presidente del Pleno; la expedición, con el visto bueno del Presidente del Pleno, de las certificaciones de los actos y acuerdos que se adopten; la asistencia al Presidente del Pleno para asegurar la convocatoria de las sesiones, el orden en los debates y la correcta celebración de las votaciones, así como la colaboración en el normal desarrollo de los trabajos del Pleno y de las Comisiones; la comunicación, publicación y ejecución de los acuerdos plenarios; el asesoramiento legal al Pleno y a las Comisiones, que será preceptivo en determinados supuestos que se detallan: cuando así lo solicite el Presidente o lo solicite un tercio del número legal de miembros de la Corporación, cuando se trate de asuntos que exijan una mayoría especial, cuando así lo exija una Ley en materias de competencia plenaria y cuando en el ejercicio de la función de control y fiscalización de los órganos de gobierno, lo solicite el Presidente o la cuarta parte, al menos, de los Concejales.

${ }^{65}$ Tal vez la explicación se encuentre en el apartado 5 del artículo 126 que declara las sesiones de la Junta de Gobierno como secretas y el deseo de que un funcionario con habilitación de carácter nacional no haya de estar necesariamente presente. La solución, como puede fácilmente imaginarse, es tremendamente incoherente si se repasa el catálogo de competencias de la Junta de Gobierno que tienen un alto contenido técnico-jurídico.
} 
la supresión de la misma. En cualquier caso, todavía más incongruente resulta la reserva de la función de apoyo a este Concejal-Secretario a un funcionario con habilitación de carácter nacional con funciones, que más que de alto contenido técnico-jurídico, se corresponden con funciones de trámite y colaboración incardinables más bien en las escalas de gestión, administrativa o auxiliar administrativa de la Administración General (artículo 169 TRRL) y que, en nada, justifican su reserva a los funcionarios con habilitación de carácter nacional ya que difícilmente son incardinables en esas funciones de interés general que la jurisprudencia constitucional consideraba justificaban la reserva de funciones (STC 214/1989, de 21 de diciembre). A saber:

- La asistencia al Concejal-Secretario de la Junta de Gobierno Local.

- La remisión de las convocatorias a los miembros de la Junta de Gobierno Local.

- El archivo y custodia de las convocatorias, órdenes del día y actas de las reuniones.

- Velar por la correcta y fiel comunicación de sus acuerdos.

No queda, de otro lado, claro en la Ley, por lo que hay que suponer que nos habremos de remitir a la legislación general reguladora del régimen jurídico de las Administraciones públicas para los órganos colegiados, quien asuma la Secretaria del Consejo Social de la Ciudad o del órgano encargado de las reclamaciones económico-administrativas ya que éstos estrictamente, y a diferencia de la Comisión de Sugerencias y Reclamaciones aunque ésta también se titula de especial, difícilmente pueden conceptuarse como una Comisión del Pleno aunque a ésta corresponda su regulación (artículo 123.1.c).

El resto de configuración organizativa plasmada en la Ley viene precedida por un alto grado de confusión sobre lo que sea un órgano administrativo y una unidad administrativa tenga o no funciones reservadas. Siguiendo el criterio de la LOFAGE los órganos administrativos son aquellas unidades administrativas a las que se les atribuyen funciones que tengan efectos jurídicos frente a terceros, o cuya actuación tenga carácter preceptivo (artículo 5.2). De otro lado, las unidades administrativas son los elementos organizativos básicos de las estructuras orgánicas con unas tareas comunes (artículo 7). Organizativamente dicha distinción se plasma en que las segundas se establecen mediante las relaciones de puestos de trabajo a diferencia de los órganos administrativos en los que éstas se insertan. Pues bien, dichos criterios me temo que no aparecen nada claros en la 
regulación establecida donde ambos criterios resultan con frecuencia mezclados y, en contradicción, con la legislación sectorial y específicamente con la relativa a los funcionarios con habilitación de carácter nacional. Analicemos las medidas adoptadas.

En lo que se refiere a las tareas de asesoramiento jurídico se crea un órgano administrativo, ya hemos aludido a ello, la Asesoría Jurídica, a la que se atribuye la asistencia jurídica, no preceptiva, al Alcalde, a la Junta de Gobierno Local y a los órganos directivos comprensiva del asesoramiento jurídico y de la representación y defensa en juicio del Ayuntamiento que, sin perjuicio de su necesidad, su razón de ser no parece ser otra que la de separar estrictamente lo que es el asesoramiento legal preceptivo del Pleno que corresponde a un funcionario con habilitación de carácter nacional ${ }^{66}$, de las tareas generales del asesoramiento jurídico que, para alguien que conozca el funcionamiento habitual de un Ayuntamiento, son sin duda más relevantes.

En cuanto a la materia económica el Proyecto de Ley preveía el desdoblamiento, ya habitual en numerosas Corporaciones, entre lo que puede entenderse como gestión económico-financiera, agrupada en ésta, de un lado, las funciones de presupuestación y contabilidad, y de otro, las de tesorería y recaudación que se atribuirán a unidades funcionalmente diferenciadas. Y, por otra parte, el órgano responsable de la función pública de control y fiscalización interna de la gestión económico-financiera y presupuestaria que es estrictamente el Interventor General Municipal. Afortunadamente, en este supuesto, el detallismo de la norma no se ha plasmado en el texto de la Ley finalmente resultante que si realiza una remisión, en estos supuestos, al Reglamento orgánico municipal y deja abierta la regulación para la determinación de si las funciones contempladas son desempeñadas por uno o más órganos.

En cualquier caso, queda reservada a funcionarios con habilitación de carácter nacional tanto el titular o titulares de la función de gestión económico-financiera y presupuestaria, salvo la del órgano que desarrolle las funciones de presupuestación y el órgano responsable de la función de control y fiscalización interna.

\footnotetext{
${ }^{66}$ Por otro lado, también seriamente desdibujada si se repara en que algunas competencias que exigían mayoría especial del Pleno se encuentran ahora radicadas en la Junta de Gobierno y, de otro lado, porque algunas materias que exigían quórum cualificado y que conserva el Pleno ya no exigen dicha mayoría.
} 
Junto a ello aparece, seguramente a fin de solucionar los graves problemas de acumulación de asuntos económico-financieros en la jurisdicción contencioso-administrativa, un órgano encargado de la resolución de las reclamaciones económico-administrativas, aunque ciertamente con funciones adicionales como el dictamen sobre los proyectos de ordenanzas fiscales y la elaboración de estudios y propuestas en materia tributaria, que, compuesto por un número impar de miembros a los que, en este caso, sólo se les exige «reconocida competencia técnica» sin ningún requisito objetivo, ciñe sus funciones a la presentadas frente a la entidad local respectiva. Pero ¿porqué sólo a ésta? ¿por qué no haber creado, dependiente de las Diputaciones Provinciales, un órgano encargado de la resolución de estas reclamaciones para todos los municipios del ámbito provincial?

\section{A MODO DE RECAPITULACIÓN Y SÍNTESIS: ALGUNAS PROPUESTAS PARA LA ESTRUCTURACIÓN DE LA FUNCIÓN DIRECTIVA EN LOS GOBIERNOS LOCALES Y LA DEFINICIÓN DE LAS FUNCIONES RESERVADAS A LOS FUNCIONARIOS CON HABILITACIÓN DE CARÁCTER NACIONAL}

Decíamos al comienzo de este trabajo que aferrarse a lo existente y no apreciar los síntomas de cambio que se producen en las organizaciones era un buen camino para no encontrar solución a los problemas que se planteaban. Y, precisamente por ello, estoy convencido de que la problemática planteada no encontrará una solución con vocación de futuro sino en la medida en que francamente nos planteemos, con la profundidad que sea necesaria, cuáles son los problemas que están en la base de la necesidad de repensar la organización local, sin apriorismos ni paradigmas, que, como en el cuento que al inicio de este trabajo les comentaba, lastran discernir sobre los cambios producidos y la mejor manera de adaptarnos a ellos.

Ciertamente, y desde su aparición, el desarrollo de las funciones atribuidas a los, queramos o no, todavía hoy denominados Cuerpos Nacionales de Administración Local no ha estado exenta de controversia. Y la discusión se ha extendido, tanto en lo que se refiere al contenido de las mismas, como a su estructuración, como al régimen singular de su dependencia. Por unas causas u otras, con mayor o menor justicia, y nos remitimos al trabajo de CARRASCo Belinchón ya citado ${ }^{67}$, su tarea se ha visto

${ }^{67}$ Coincidiendo con la perspectiva que se mantiene en este trabajo en cuanto a la necesidad de 
normalmente desenvuelta entre dos puntos de tensión: la necesidad e importancia de las funciones que desarrollaban y, de otro lado, la permanente desconfianza hacia un funcionario, hasta cierto punto extraño a la entidad local en que prestaba sus servicios por su distinta dependencia orgánica y funcional. Lo cierto es que, muy a menudo, se ha olvidado la generalizada contribución que han realizado y realizan estos funcionarios para el ejercicio de la acción de gobierno en tantas localidades ${ }^{68}$.

Las claves para el futuro, por tanto, tampoco estarán exentas de polémica, de opiniones contradictorias entre sí, y de mil y una soluciones y propuestas. Seguramente, pues curiosamente es una constante en los trabajos que vienen publicándose desde hace décadas, también seguiremos preguntándonos con cierto pesimismo sobre qué futuro profesional es el que espera a estos funcionarios. Desde luego el futuro inmediato, al menos en cuanto a la Escala de Secretaria en las entidades locales que hayan de adoptar la organización específica contemplada en la Ley, no puede ser visto positivamente. Como se ha expuesto las dos funciones claves sobre las que pivota dicha función tienen una clave común: no se encuentran reservadas sino parcialmente a dichos funcionarios.

Desde mi punto de vista, creo que convendría reflexionar sobre algunos puntos si se quiere discernir por donde pueden ir las tendencias en los próximos años.

adaptación de las funciones de habilitación de carácter nacional, J. CARRASCo BELINCHÓN, op. cit., pág. 38 alude, haciendo una reflexión sobre el futuro de éstas que se advierte solo parcialmente se comparte, a que «En efecto, en las pequeñas Corporaciones, su vertiente de funcionario técnico será la primordial, en tanto que en las medianas y grandes lo fundamental tiene que ser su figura directiva, y en ambas debe caracterizarle el ser el impulsor de los servicios y el catalizador del desarrollo comunitario. En consecuencia, creemos que el porvenir del Secretario no depende de retocar su configuración actual añadiéndole cometidos minúsculos, pues esto supondría caminar fatalmente hacia su progresiva depreciación. En este sentido, podríamos sostener que el aferrarse a la pluma secretarial, es tanto como firmar con ella la sentencia de muerte del Cuerpo, o al menos, el certificar su supervivencia vegetativa». Y añade, proponiendo otras alternativas, que «En cambio, el centrar la función en el asesoramiento, es brindar al Secretario una base de lanzamiento hacia los más altos horizontes».

\footnotetext{
${ }^{68}$ Aunque, ciertamente, en cuanto a la naturaleza de las funciones de habilitación de carácter nacional no parece haber duda de que se trata de funcionarios locales, a los cuales el Estado se limita a habilitar para ocupar los puestos de trabajo a ellos reservados dada la trascendencia de su función que rebasa el interés local, supralocal o supracomunitario (STC 214/1989). No obstante, el Estado se reserva ciertas funciones, declaración de situaciones disciplinarias o régimen disciplinario, respecto de los mismos que determinan que pueda afirmarse que existe con respecto al Estado una relación de servicio. Puede verse, con relación a este punto, el trabajo de A. BALLESTEROS FERNÁNDEZ, «Las funciones reservadas a los Funcionarios con habilitación nacional», trabajo incluido en la serie Documentos INAP La función pública local y la habilitación nacional, INAP, Madrid, 1995, págs 28 y 29.
} 
En este sentido, las conclusiones de los Grupos de trabajo realizados en el marco de un Seminario específico convocado por el Instituto Nacional de Administración Pública en 1997 son importantes de subrayar en relación con lo expuesto. Me refiero, específicamente, a las conclusiones generales que en ese marco se abordaron y que pueden reconducirse, por motivos de brevedad, a las tres siguientes:

- Las funciones reservadas a la habilitación nacional no son independientes de la diversidad de nuestra Administración local ni de la complejidad del modelo territorial en el que se inscribe.

- Las funciones desarrolladas son de alta responsabilidad, se corresponden con un ámbito profesionalizado en torno a núcleos de competencia profesional.

- La función directiva no es un elemento unívoco en la organizaciones locales y dichas funciones son residenciables en un ámbito de geometría variable de la dirección pública.

Y es que, en efecto, conviene partir de un dato ya reflejado en este trabajo y que no es otro que la importante transformación que nuestros Gobiernos locales han sufrido en estos últimos años y el relativo poco evolucionado contexto constitucional y normativo en que se desenvuelven. Fuera de episodios de novela rosa y de casos excepcionales de corruptela o nepotismo, nuestras entidades locales no pueden diagnosticarse de idéntica forma a cómo lo eran a principios del siglo pasado lo que precisamente motivó el nacimiento, al menos con las características definitorias con que hasta hoy los conocemos, de estos Cuerpos. Tampoco la situación de dichas entidades locales en el marco constitucional y europeo es la misma tras el reconocimiento de principios como el de autonomía local o el de subsidiariedad, ni en relación a las funciones y competencias que desarrollan, ni tampoco en lo relativo a sus relaciones con otras Administraciones territoriales cuyo ejercicio de tutela se ve constreñido al marco de la legalidad ${ }^{69}$. Igualmente podría decirse de la organización administrativa que poseen, de sus capacidades de reclutamiento y formación, de la función pública profesionalizada que las sirve, etc... En definitiva, los mismos marcos de análisis que se utilizaron a principios de siglo, y más decisivamente, en la década de los setenta para estructurar estas funciones han

\footnotetext{
${ }^{69}$ L. Morell OcaÑa, op. cit., pág. 19, pone de relieve, en este sentido, que tras la Constitución de 1978 «se puede observar con claridad que el modelo de funciones de los Cuerpos Nacionales estaba demasiado cerca de los quehaceres y problemas del Estado del s. XIx. Ese Estado quería introducirse en el control de las actividades locales mediante la sustantivación de Cuerpos de funcionarios poseedores de esos mecanismos de control y directamente dependientes del propio Estado».
} 
quedado francamente obsoletos. Nuestros Gobiernos locales han cambiado enormemente y a esta realidad han de adaptarse cualesquiera soluciones que se adopten.

En segundo lugar, creo que es importante reflexionar sobre las funciones desarrolladas y el marco organizativo en que las mismas se desempeñan. Y es que, efectivamente, la función viene definitivamente determinada por el marco organizativo en que se desarrolla en primer término. Quiero decir, que aunque de contenido idéntico en su denominación, el desarrollo de las funciones reservadas adquiere perfiles propios según a qué municipios nos refiramos. Que es un hecho ineludible que en municipios pequeños y medianos el Secretario-Interventor o, en municipios de mayor población, el Secretario y el Interventor, junto a las funciones estrictamente atribuidas, desarrollan funciones directivas y gestoras necesarias en la organización administrativa es algo que es preciso poner de relieve porque seguramente las soluciones que se adopten no puedan ser uniformes ${ }^{70}$.

De otro lado, es notorio que las funciones atribuidas a las distintas Subescalas en que se estructuran estos funcionarios tampoco son uniformes entre sí y, en mi opinión, es preciso partir de las diferencias existentes entre la fe pública, el asesoramiento jurídico, las funciones de control interno y fiscalización y las funciones atinentes a la presupuestación, contabilidad, tesorería y recaudación, pues tales diferencias marcan decisivamente el régimen de garantías que para su desempeño efectivo haya de atribuírseles. No basta, a estos efectos, precisar que son funciones públicas necesarias en todas las entidades locales. Por supuesto que sí, pero también otras son imprescindibles y no por ello se reservan a unas Escalas en que la selección e importantes atribuciones respecto de estos funcionarios quedan en manos de la Administración estatal.

Pero, asimismo, otras cuestiones en relación con dichas funciones han de ser planteadas y lo han de ser porque, finalmente, son las que están en la base de la discusión que sobre estos funcionarios se ha producido en las últimas décadas. La primera de ellas consiste en determinar si, efectivamente, la problemática planteada lo es en relación con la función a desarrollar y los requerimientos y garantías que ésta exige o si se deriva de otras consideraciones. Ciertamente el desempeño de las mismas, en opi-

\footnotetext{
${ }^{70} \mathrm{Y}$ dicha reflexión, bien es verdad que con soluciones diversas, es compartida por la mayoría de los especialistas que se han acercado al problema. Ya se trate de Morell OCAÑa (pág. 20), Ángel Ballesteros (pág. 33) o Salanova Alcalde (pág. 40) en los trabajos anteriormente citados ésta es una coincidencia uniforme.
} 
nión del Tribunal Constitucional, rebasa el interés estrictamente local e, inclusive, autonómico, pero ¿No es esta una perspectiva preconstitucional más apegada a una desconfianza sobre el Gobierno local más propia de otras épocas que a una concepción autónoma del Gobierno local?

Es más, incluso deberemos preguntarnos ¿por qué han de ser reservadas a un Cuerpo o Escala de funcionarios específica? ¿Puede predicarse dicha reserva con igual intensidad respecto de todas las funciones desarrolladas? ¿Tiene sentido el artificioso deslinde entre las tareas de asesoramiento jurídico y asesoramiento legal preceptivo? Por decirlo en las claves del cuento con que inicié esta exposición, ¿no estaremos tratando de preservar algo que ha cambiado sustancialmente? y, con arreglo a ello, ¿no deberíamos buscar otras oportunidades más realistas de desempeño de esas funciones? La realidad es que lo cierto, y si nos ceñimos a la funciones de la Secretaria al menos en las Corporaciones afectadas por ese nuevo sistema de organización implantado en las Corporaciones afectadas por el Proyecto de Ley, es que la misma no pasa de ser, en cierta medida, una figura decorativa que puede ser ceñida a funciones en exceso apegadas a lo simbólico.

Por último, y como en su momento ya anuncié, no considero que esta cuestión pueda tratarse al margen ni de la estructuración de la función directiva ni, asimismo, de una eventual reforma del marco jurídico en que se desarrolla la función pública local, pues es en este marco donde se desarrollan las funciones reservadas a esta habilitación. Y es que la realidad muestra que la función pública local vive, también claramente, anclada en una visión preconstitucional. De hecho, su estructura y funciones encuentran anclaje, con importantes disfunciones sobre el sistema de empleo público establecido en la reforma de 1984, en el RD Legislativo 3046/1977, de 6 de octubre, al que hizo pervivir en buena medida el Texto Refundido de Régimen Local de 1986.

Y en esta última reflexión no es ajeno el Estado que, como a mi juicio debería haber realizado, no ha renunciado, antes bien al contrario como lo demuestra las últimas disposiciones sobre qué es básico introducidas en la Ley de Presupuestos Generales del Estado para el año 2003, a estructurar la función pública local desde una perspectiva uniforme $-\mathrm{y}$ seguramente alejada de las funciones y servicios que prestan nuestras entidades locales- y a impedir con ello, al mismo tiempo, la eventual imbricación de la función pública local con la función pública autonómica introduciendo criterios de racionalidad y optimización de los recursos humanos disponibles en el ámbito territorial afectado. Y dicha visión supone importantes problemas en materia de movilidad, carrera administrativa, reserva de fun- 
ciones públicas, selección de funcionarios e impide construir una función pública común, que presta servicios indistintamente en la Administración autonómica, local y universitaria, en cada Comunidad Autónoma.

Pero tampoco están exentos de responsabilidad nuestros Gobiernos locales. El batiburrillo que ofrece la propia organización en cada Gobierno local, con la desnaturalización de los instrumentos organizativos existentes, la distinta estructuración de escalas y funciones reservadas en cada uno de ellos y, en fin, la desordenada articulación, inclusive en elementos indisponibles del sistema, de la función pública local mueven también a la necesaria reflexión sobre el sistema.

Junto al punto anterior la función directiva en nuestras entidades locales, y las soluciones que a éste se le otorguen, es otro punto que no está al margen del debate. Ciertamente, y en la medida que la función directiva no sea un espacio profesionalizado y quede sujeto no a la competencia profesional sino a la confianza política, difícilmente este marco servirá para encuadrar estas funciones que, aunque de alta responsabilidad, no cabe duda que se encuentran insertas, junto a otras, en el espacio profesional superior de las organizaciones locales y la indefinición de ese espacio, y su colonización por un personal de extracción política, alimenta sin duda el debate sobre este ámbito profesionalizado y no introducen el necesario rigor en su tratamiento.

Y es desde la necesaria conciliación y racionalización de estos puntos a que nos hemos referido desde donde habrá de partirse para llegar a una conclusión más aceptable que la adoptada en esta Ley que, si bien reconoce un espacio directivo lo que sin duda es loable, una vez más parece que dejará pasar una oportunidad para abordar con la seriedad que merece la organización administrativa de nuestras entidades locales, la estructuración de la función directiva en nuestras entidades locales y dar una respuesta definitiva a la problemática planteada por las funciones reservadas a habilitados nacionales. 